\title{
Common Protective Strategies in Neurodegenerative Disease: Focusing on Risk Factors to Target the Cellular Redox System
}

\author{
Patrizia Hrelia $\left(\mathrm{D},{ }^{1}\right.$ Giulia Sita ${ }^{(D)},{ }^{1}$ Marina Ziche $(\mathrm{D}),{ }^{2,3}$ Emma Ristori $(\mathrm{D}),{ }^{2,3}$ Angela Marino ${ }^{(D)},{ }^{4}$ \\ Marika Cordaro $\left(\mathbb{D},{ }^{5}\right.$ Raffaella Molteni ${ }^{(D)}{ }^{6}$ Vittoria Spero ${ }^{(D)},{ }^{6}$ Marco Malaguti $\left(\mathbb{D},{ }^{7}\right.$ \\ Fabiana Morroni $\left(\mathbb{D},{ }^{1}\right.$ and Silvana Hrelia $\mathbb{D D}^{7}$ \\ ${ }^{1}$ Department of Pharmacy and Biotechnology, Alma Mater Studiorum, University of Bologna, 40126 Bologna, Italy \\ ${ }^{2}$ Department of Medical Science, Surgery and Neuroscience, University of Siena, 53100 Siena, Italy \\ ${ }^{3}$ Toscana Life Sciences, 53100 Siena, Italy \\ ${ }^{4}$ Department of Chemical, Biological, Pharmaceutical and Environmental Sciences, University of Messina, 98166 Messina, Italy \\ ${ }^{5}$ Department of Biomedical and Dental Sciences and Morphofunctional Imaging, AOU Policlinico Universitario "G. Martino", \\ 98125 Messina, Italy \\ ${ }^{6}$ Department of Medical Biotechnology and Translational Medicine, University of Milan, 20129 Milan, Italy \\ ${ }^{7}$ Department for Life Quality Studies, Alma Mater Studiorum, University of Bologna, 47900 Rimini, Italy \\ Correspondence should be addressed to Fabiana Morroni; fabiana.morroni@unibo.it
}

Received 11 May 2020; Accepted 15 July 2020; Published 3 August 2020

Academic Editor: Andrey V. Kozlov

Copyright (C) 2020 Patrizia Hrelia et al. This is an open access article distributed under the Creative Commons Attribution License, which permits unrestricted use, distribution, and reproduction in any medium, provided the original work is properly cited.

\begin{abstract}
Neurodegenerative disease is an umbrella term for different conditions which primarily affect the neurons in the human brain. In the last century, significant research has been focused on mechanisms and risk factors relevant to the multifaceted etiopathogenesis of neurodegenerative diseases. Currently, neurodegenerative diseases are incurable, and the treatments available only control the symptoms or delay the progression of the disease. This review is aimed at characterizing the complex network of molecular mechanisms underpinning acute and chronic neurodegeneration, focusing on the disturbance in redox homeostasis, as a common mechanism behind five pivotal risk factors: aging, oxidative stress, inflammation, glycation, and vascular injury. Considering the complex multifactorial nature of neurodegenerative diseases, a preventive strategy able to simultaneously target multiple risk factors and disease mechanisms at an early stage is most likely to be effective to slow/halt the progression of neurodegenerative diseases.
\end{abstract}

\section{Introduction}

Neurodegenerative diseases define diversified chronic disorders related to the progressive motor, sensory, and perceptual dysfunctions which lead to cognitive and behavioural deficits. In these pathologies, the selective neuronal cell loss appears in the adulthood, within different areas of the brain [1]. Neurodegenerative diseases are usually divided into two main groups, chronic and acute disorders [2]. In particular, Alzheimer's disease (AD), Parkinson's disease (PD), Huntington's disease (HD), amyotrophic lateral sclerosis (ALS), and so forth, share a plethora of features like oxidative stress, glycation, abnormal protein deposition, inflammation, and progressive neuronal loss [3-5]. It is interesting to highlight that, several years later traumatic brain injury (TBI) or stroke, patients have shown an increased incidence of neurodegenerative chronic diseases [6-9]. In particular, after TBI, many patients show motor and cognitive manifestations similar to those observed in $\mathrm{AD}$ and $\mathrm{PD}$ patients [10-12]. During the last century, a growing research interest has been addressed to the identification of mechanisms and risk factors leading to the complex etiopathogenesis of 
neurodegenerative diseases, including not only genetic, vascular, and metabolic but also lifestyle-related factors, which often coexist and interact with each other [13-15].

In view of the complex multifactorial nature of neurodegenerative diseases, interventions that simultaneously target multiple risk factors and disease mechanisms at an early stage of the diseases are most likely to be effective. Among the matrix of factors which could delineate the possible pathogenesis of neurodegenerative diseases, aging is the primary risk, and also, cerebrovascular diseases, diabetes, and inflammation define steps in this inexorable complex cascade [16]. The effects of the different risk factors depend on the patient's age at treatment, indicating that the timing of preventive interventions needs to be carefully considered.

Inflammation is one of the key connectors linking vascular abnormalities and neurodegeneration. Indeed, inflammation, especially of the endothelium, is central to the initiation and progression of a broad spectrum of age-related neurodegenerative diseases [17], and it has been demonstrated to clearly affect the expression of Brain-Derived Neurotrophic Factor (BDNF) within the brain [18]. Neuroinflammation is a key factor in both acute and chronic conditions [1921]. In the central nervous system (CNS), cellular infiltration in response to inflammation, infection, and injury is weaker and delayed than in other tissues, but microglia, and the expression and release of classical inflammatory mediators, such as acute-phase proteins, eicosanoids, complement, and cytokines, can be induced rapidly [22-24].

Moreover, redox signalling dysregulation has been recognized as a contributing factor in several age-related diseases and is responsible for endothelial dysfunction in the majority of pathophysiological conditions [25, 26]. Several studies established that radical detoxification pathways are key homeostatic mechanisms associated with vasoprotection in aging and chronic degenerative diseases [27-29]. In addition, oxidative stress is also correlated with the impairment of blood glucose regulation [30].

Nuclear factor (erythroid-derived 2)-like 2 (Nrf2) and nuclear factor $-\kappa \mathrm{B}(\mathrm{NF}-\kappa \mathrm{B})$ are two interconnected master regulators of cellular responses to oxidative stress and inflammation, respectively [31]. Recently, several studies demonstrated that dysfunctions in redox homeostasis are a common mechanism in cardiovascular, neurological, and metabolic diseases [32, 33]. However, oxidative stress was hitherto not pharmacologically targetable, and the only strategy tested so far, using antioxidants, was unsuccessful or even harmful. Interestingly, small molecules, now become available, are able to interact with specific targets and useful for therapeutic proof-of-concept studies. In this view, the importance of investigating the complex interrelated molecular mechanisms behind neurodegenerative disease onset and progression appear undeniable. In an attempt to characterize the complex network of molecular mechanisms underpinning acute and chronic neurodegeneration, this review is focused on the disturbance in redox homeostasis, as common mechanism behind five pivotal risk factors: aging, oxidative stress, inflammation, vascular injury, and glycation.

\section{The Role of Aging and Oxidative Stress in Chronic Neurodegenerative Diseases}

$\mathrm{AD}$ is the leading cause of dementia worldwide, accounting for $60-70 \%$ of cases (http://www.who.int/mediacentre/ factsheets/fs362/en/), although increasing evidence shows that mixed brain pathologies (AD and vascular) account for most dementia cases in the old age $[34,35]$. Previous intervention efforts focused on the management of single risk factors with relatively modest findings.

Undoubtedly, aging is the primary risk factor for neurodegenerative diseases, and age-related changes in cellular function predispose to the pathogenesis of different pathological conditions, as AD. The EU population aged 65 and over is expected to double by 2030 and to triple by 2050 [36]. Aging not only makes patients more susceptible to neurodegenerative diseases but also impairs self-repair abilities. The number of people living with neurodegenerative diseases worldwide is currently estimated at 50 million (http://www .who.int/mediacentre/factsheets/fs362/en/). The economicsocial burden of neurodegenerative diseases is devastating not only for the patients but also for their families and caregivers. Indeed, the huge cost of the diseases will challenge health systems to deal with the predicted future increase of prevalence. Thanks to the advances in molecular biology, our knowledge of aging and cognitive decline constantly increases. Many signalling pathways involved in the regulation of aging and lifespan have been identified, and recent studies have demonstrated the involvement of these signalling pathways in age-related cognitive decline [37, 38]. These pathways may represent important targets to develop novel and effective disease-modifying drugs to treat, delay, or prevent age-related neurodegenerative diseases.

Unfortunately, to date, no effective treatments are available to slow or stop the death and malfunction of neurons in the brain that cause disease symptoms and make the disease fatal. In this view, discovering new strategies and drugs to slow down the onset and the progression of neurodegenerative diseases is a primary goal, and it could have significant social and economic impacts. $\beta$-Amyloid $(\mathrm{A} \beta)$ plaque depositions and neurofibrillary tangle (NFT) accumulation not only are referred to as neuropathological hallmarks of $\mathrm{AD}$ but also have been widely implicated and described in the healthy aging process [39-41]. The chronic increase of oxidative stress has been recognized as a key contributing factor in aging and in several age-related diseases. Indeed, the "oxidative stress theory of aging" considers the functional impairments associated with aging, due to the accumulation of oxidative damage to lipids, DNA, and proteins by reactive oxygen species (ROS) and reactive nitrogen species (RNS). However, the exact mechanism by which oxidative stress induces aging is still not defined. Perhaps, the enhanced levels of ROS and RNS lead to cellular senescence, which involves the secretion of soluble proinflammatory factors and degradative enzymes [42]. In this area, S-nitrosylation, a covalent reaction of a nitric oxide $(\mathrm{NO})$ group with a reactive cysteine thiol group on target proteins, has emerged as the principal mechanism exerting NO bioactivity [43]. SNitrosylation regulates protein function and can mediate 
either protective or neurotoxic effects depending on the action of the target protein [44]. Under physiological conditions, NO production induced by GMPc activation generates mitochondrial biogenesis through peroxisome proliferator-activated receptor $\gamma(\operatorname{PPAR} \gamma)$ coactivator. In contrast, increased nitrosative stress can result in defects in mitochondrial function. For example, S-nitrosylation affects mitochondrial respiration by inhibiting complexes I and IV [45]. Interestingly, Cho et al. demonstrated that S-nitrosylation of Drp1 mediates $\mathrm{A} \beta$-induced disruption of mitochondrial dynamics, contributing to synaptic injury and neuronal damage [46]. Thus, protein modifications produced by RNS may impair mitochondrial health and further induce synaptic dysfunction and neuronal death. Indeed, another feature of $\mathrm{AD}$ brains is mitochondrial dysfunction $[47,48]$, characterized by an increase in mitochondrial membrane permeability and loss of membrane potential and associated with the release of cytochrome $c$ $[49,50]$. Interestingly, Antequera et al. [51] found a reduction in the expression levels of mitochondrial complexes I and III. They speculate that this mitochondrial dysfunction is probably because $\mathrm{A} \beta$-related mitochondrial dysfunction is exacerbated by aging and may be one of the mechanisms explaining the pronounced accumulation of $\mathrm{AD}$ pathology with aging. The hypothesis is that the increasing levels of $\mathrm{A} \beta$ and the aging process in $\mathrm{AD}$ patients could be considered responsible for the senescent phenotype involving also endothelial cell (EC) dysfunction and characterized by increased oxidative stress [42]. In a recent study, Zhu et al. showed that in an aging mouse model (SAMP8), the cognitive impairment, inflammation, and oxidative stress were efficiently counteracted by the treatment with ligustilide, the most biological active component present in Angelica sinensis, a perennial plant that belongs to the Umbelliferae family [52]. Several studies have shown the ability of ligustilide to cross the blood-brain barrier (BBB) and to reach the CNS where the active could exert its antiapoptotic and antioxidative effects [53, 54]. The fundamental role of oxidative stress in neurodegenerative disorders is recognized, and, also in the early stages, it is possible to observe a significant increase of ROS production [55]. When this phenomenon is efficiently reduced, also the cognitive impairment and the inflammatory processes are successfully counteracted [56, 57]. Indeed, there is a close relationship among oxidative stress, aging, and inflammation.

During aging, the chronic oxidative stress enhances the loss of homeostasis, involving in particular the regulatory systems, as the immune response. This condition activates the inflammation that, in turn, increases oxidative stress generating a vicious circle [58]. A recent study has shown that increased levels of biomarkers for oxidative stress are related to high levels of inflammatory cytokines, and both are ascribed to poor cognitive performance in aged patients [59]. Several studies have shown that cognitive decline is slower when endogenous antioxidant systems, as glutathione peroxidase (GSH-Px), are high. On the contrary, high levels of GSH accelerate cognitive impairment in aged patients $[55,60]$. This is a controversial event, because GSH is known as an endogenous protection against intracellular oxidative stress. An explanation could be that, as GSH is a substrate of GSH-Px, the increasing of GSH levels may be due to the increase of oxidative stress related to the reduction of GSHPx activity [61]. The increased level of oxidative stress was observed also in human peripheral blood mononuclear cells isolated from individuals with mild cognitive impairment and from 3-month-old 3xTg-AD male mice, which was probably due to the increased levels of the Nrf2 and reduced superoxide dismutase 1 (SOD1) mRNA in the brain cortex [62]. It is known that Nrf2 is referred to as the principal regulator of the cellular response to oxidative and toxic insults, modulating the expression of hundreds of genes responsible for the immune and inflammatory responses, cellular metabolism and metabolic regulation, and even cognitive dysfunction and addictive behaviour [63]. The regulation of Nrf2 is complex and controlled not only by the repressor protein Kelch ECH associating protein 1 (Keap1) but also by other signalling pathways, including glycogen synthase kinase 3 (GSK-3), NF- $\kappa$ B, NOTCH, and AMP kinase [60, 64, 65]. Due to the role of Nrf2 deregulation in neurodegenerative diseases, Nrf2 inducers are currently under investigation. The AT-Nrf2-knockout mouse model, which combines amyloidopathy and tauopathy with Nrf2 deficiency, presents increased markers of oxidative stress and neuroinflammation in the brain tissue compared to wild-type mice [66]. Furthermore, young adult AT-Nrf2-knockout mice have shown deficits in spatial learning and memory and reduced longterm potentiation. Transcriptomic analysis has shown that Nrf2-knockout mouse brains share 7 and 10 of the most dysregulated pathways with aging humans and $\mathrm{AD}$ brains, respectively [66].

\section{Neuroinflammation and Aging: Role of Acute Injury and Impact on Neurotrophins}

Among the principal causes of acute brain injury, TBI and stroke are the most relevant. TBI is a highly complex disorder caused by both primary and secondary injury mechanisms $[67,68]$. Primary injury mechanisms result from the mechanical damage of neurons, axons, glia, and blood vessels as a result of shearing, tearing, or stretching. Secondary injury mechanisms include a wide variety of processes such as depolarizations and disturbances of ionic homeostasis [69], release of neurotransmitters (e.g., glutamate excitotoxicity) [70], mitochondrial dysfunction [71], neuronal apoptosis [72], lipid degradation [73], and initiation of inflammatory and immune responses [7, 74].

Likewise, strokes can be classified into two main types: ischemic or haemorrhagic. In the first case, the neurological dysfunction is caused by focal cerebral, spinal, or retinal infarction. The haemorrhagic stroke can be classified as subarachnoid haemorrhage (SAH), with haemorrhage from a cerebral blood vessel, aneurysm, or vascular malformation located into the subarachnoid space, or as intracerebral haemorrhage (ICH), when a weakened blood vessel within the brain bursts, allowing blood to leak and increasing intracranial pressure, causing damage to the brain cells surrounding the blood [75-77]. 
Posttraumatic neuroinflammation is characterized by oxidative stress, glial cell activation, leukocyte recruitment, and release of inflammatory mediators [74], as hereafter reported. High ROS levels cause lipoperoxidation of cell membrane, leading to dysfunction of mitochondria and oxidizing proteins [78]. After injury, endogenous inflammatory responses are activated to protect the damaged area from invasion of pathogens and to restore injured cells. In this condition, the complement system is activated, followed by the invasion of monocytes, neutrophils, and lymphocytes through the $\mathrm{BBB}$ [79], with consequent production of prostaglandins, proinflammatory cytokines, free radicals, and several inflammatory elements. Microglia are the primary innate immune cells in the CNS and represent the first line of defence following brain injury [80]. On the other hand, when microglia become overactivated or reactive, they can induce detrimental neurotoxic effects by releasing multiple cytotoxic substances, including proinflammatory cytokines and oxidative metabolites [81]. Further, the release of proinflammatory cytokines and other soluble factors by activated microglia can significantly influence the subsequent activation of astrocytes [82].

Upon activation, astrocytes upregulate several neurotrophic factors (e.g., BDNF) that protect against cell injuries [83]. In addition, astrocytes play a crucial role in regulating excitotoxicity by reducing neuronal glutamate levels [84]. These alterations may lead to secondary neurological disease, such as ischemia and epilepsy [85]. After injury, neutrophils are the first immune cells that undergo conformational changes and migrate through the endothelial vessel wall to invade the damaged tissue [86]. Following an ischemic injury, neutrophils cause secondary injury by releasing proinflammatory factors, ROS, proteases, and matrix metalloproteinases (MMPs) [87]. These toxic factors impair EC membrane and basal lamina leading to the increase of BBB permeability [23]. In addition, leukocytes potentiate ischemic injury blocking erythrocytes' flow and then activating the production of proteases, MMPs, and ROS that can significantly damage blood vessels and brain tissues. Finally, infiltrated leukocytes infiltrated further exacerbate neuronal injury by activating proinflammatory factors in and around the penumbra and the infarct core $[23,88,89]$. Cytokines upregulate the expression of cell adhesion molecules (CAM) [90, 91], as the intracellular adhesion molecule 1 (ICAM 1) in the ischemic core which leads to BBB disruption [23]. The three major proinflammatory cytokines are tumor necrosis factor-alpha (TNF- $\alpha$ ), interleukin $1 \beta$ (IL- $1 \beta$ ), and IL- 6 that contribute to the inflammatory response after brain injury $[92,93]$. Under certain stimuli, TNF- $\alpha$ is synthesized and released by astrocytes, microglia, or neurons and is involved in the BBB permeability and in the modulation of synaptic transmission and plasticity [94-96]. After the formation of an inflammasome, IL- $1 \beta$ can activate NF- $\kappa$ B via toll-like receptors (TLRs) allowing the nuclear factor to transactivate genes associated with cytokines, chemokines, and other proinflammatory mediators. In addition, IL- $1 \beta$ can prime the endothelium for increased leukocyte adherence and edema formation [97]. Additionally, Yang and colleagues demonstrated that IL- 6 serves as an amplification signal for the inflammatory response and motor coordination deficits after brain injury [98].

Age at injury is likely to influence the way the brain is able to repair itself as a result of developmental status, extent of cellular senescence, and injury-induced inflammation [99102]. Hoane and colleagues and Sohrabji showed that aging increased tissue loss compared to young animals following TBI and also state that aging is the principal risk factor for ischemic stroke $[103,104]$. This is probably due to the functional changes that happened in the $\mathrm{BBB}$ as a result of brain injury, including decreased trafficking of peripheral immune cells into the brain parenchyma and increased oxidative stress and inflammatory mediator release that lead to an amplification of the inflammatory response in the injured brain [105]. For this reason, the understanding of cellspecific changes in an aging brain will be critical for the development of next-generation drug therapies.

As the molecular mechanism of aging in mice is similar to that in humans [95], mouse models have been often used in the field of neurodegenerative diseases associated with aging [106]. In particular, studies have been conducted to better focus on major risk factors for PD, reportedly associated with aging [107]. In this regard, Crupi et al. already reported about PD modelled on old mice by 1-methyl-4-phenyl-1,2,3,6-tetrahydropyridine (MPTP). In particular, old MPTP-intoxicated mice (21 months old) and young MPTP-intoxicated mice ( 3 months old) were both subjected to behavioural testing and brain processing eight days after MPTP administration [108]. The authors demonstrated a more significant nigrostriatal dopamine (DA) degeneration than that observed in young MPTP-treated mice. Moreover, anxiety-like behaviour was more evident in MPTP-treated old mice. In this context, the aim of the authors was to define a time window for applying therapeutic treatment to effectively counteract neurodegenerative processes associated with age-related diseases. As a matter of fact, current therapies do not address neuroinflammation but, though neuroinflammation may worsen $\mathrm{PD}$ disease progress, they are focused on ameliorating the symptoms of DA loss rather than the mechanisms underlying DA neuron damage [109].

As neurodegenerative diseases, associated with inflammation and oxidative stress, may develop as a consequence of brain trauma, studying the onset of neurodegeneration in MPTP mouse models, in young and aged animals, can be considered a good basis. In this context, Calabrese et al. state that peripheral and/or central inflammatory stimuli, affecting the brain, could induce inflammatory changes leading to PD symptoms and progression [107].

The abnormal neuroinflammatory response and oxidative stress may have a detrimental impact on neuroplasticity, the ability of the brain to perceive and respond to an external or internal stimulus through an adaptive mechanism, which is compromised in several neurodegenerative disorders [110]. This CNS capability to shape its structure and function for a proper coping relies on the integrated involvement of different molecular systems, among which the neurotrophic factors plays a crucial role. Indeed, it is well known that the diversity and specialization of the CNS resident cellular populations are due to many complex processes. Proliferation, 
differentiation, growth, migration, synaptic formation, and modification are mainly carried on by neurotrophic factors, in particular by neurotrophins (NTs). NTs are a group of polypeptide growth factors secreted by different brain cell populations, such as microglia cells, oligodendrocytes, astrocytes, and neurons. The NT family comprehends different but similar polypeptides: the nerve growth factor (NGF), BDNF, NT-3, and NT- $4 / 5$, as well as the more recent NT-6 and NT-7. Their activity is mediated by the binding to specific transmembrane receptors, the tropomyosin receptor tyrosine kinases (Trk receptors) and the p75 NT receptor. NTs have different binding affinities for specific receptors: NGF binds to TrkA, BDNF and NT-4 to TrkB, and NT-3 to TrkC, whereas all four NTs can bind to the p75 receptor. Furthermore, the association of p75 with Trk receptors can increase the selective affinity of the second ones for each respective NT $[111,112]$. Nowadays, the role of NTs for the survival of developing neurons is well consolidated [113, 114]; however, in the last decades, the focus of the research has moved on their function as mediators of neural and synaptic plasticity in the adult brain. In particular, BDNF has emerged for its role in a wide range of neurophysiological processes, peculiar activity-dependent regulation, and because of its abundance in brain regions involvement in neuroplasticity throughout the lifespan. The wide spectrum of activity in which BDNF is involved relies to its complex genetic structure that has been characterized in detail [115, 116]. BDNF gene contains multiple promoters that drive the expression of several transcripts bearing different noncoding exons. Interestingly, different isoforms of BDNF are expressed in different subcellular compartments; for example, exon IV mRNAs have been detected in the soma and dendrites while exon III expression is restricted to the cell body [117]. It is important to note that the transcripts that target the dendritic area may promote fast local translation of the pro- and mature BDNF, producing an effect strictly linked to the synaptic structure and activity $[118,119]$. The synthesis of the mature BDNF is likewise a complex process, involving different precursor isoforms and different possible pathways to reach the mature form. The pro-BDNF protein, indeed, can be cleaved both in the intracellular space, in the intracellular secretory vesicles, or after secretion, through distinct mechanisms. Pro-BDNF is also an active precursor, which is able to bind the p75 neurotrophin receptor and the sortilin receptor, while mature BDNF binds p75 receptor and, preferentially, TrkB [120]. Upon binding with BDNF, TrkB initiates dimerization and autophosphorylation. Once phosphorylated, TrkB activates a series of intracellular pathways: the phosphatidylinositol 3-kinase/protein kinase B- (PI3K/Akt-) related pathways, which exert antiapoptotic and prosurvival activities and modulate N-methyl-D-aspartate receptor- (NMDAR-) dependent synaptic plasticity [121-123]; the PI3K/Akt/mammalian target of rapamycin (mTOR) cascade that, through regulation of protein synthesis and cytoskeleton development, enhances dendritic growth and branching $[124,125]$; the mitogen-activated protein kinase (MAPK)/Ras signalling cascade that regulates protein synthesis during neuronal differentiation [126]; and many others.
Given the crucial physiological role that BDNF exerts through the above-described mechanisms on several processes known to be compromised in neurodegenerative disorders, such as neuronal survival and cognition, several clinical and preclinical studies have investigated the impact of the risk factors for these diseases on BDNF function, in particular focusing on the influence of aging. The obtained results clearly underline a relationship not only between aging and deficit in neuroplasticity but also between BDNF alteration and frailty, the fragility that may underline neurodegenerative diseases in the elderly [127]. Indeed, it is important to note that some individuals are able to reach advanced age with the cognitive functions mainly intact whereas others develop a condition of frailty, characterized by an increased general vulnerability probably due to microtraumas and detrimental events accumulated during life. Furthermore, even the high-functioning elder people who experience an acute injury (such as TBI or stroke), a stress, or an infection become at higher risk to develop a transient or permanent cognitive impairment, which may in turn result in dementia and other symptoms of neurodegenerative diseases. To the current knowledge, the cognitive impairment observed in the aged population is due-at least in part-to structural and physiological changes in the brain. During aging, these processes undergo a physiological decline, and structural changes in neurons and spines as well as alterations in neurotransmitter receptor expression and changes in electrophysiological properties occur, causing an increased vulnerability to neurobiological diseases [128].

In the attempt to explain what is observed during aging, a negative correlation between BDNF serum levels and aging has been found in healthy subjects [129]. Moreover, the hippocampal volume of 142 healthy subjects between 59 and 81 years old has been measured and correlated with serum BDNF levels and memory performances finding that increasing age was associated with smaller hippocampal volumes, reduced levels of serum BDNF, and poorer memory performances [130]. Furthermore, a postmortem study on healthy subjects aged between 16 and 96 years confirmed the negative correlation between BDNF and age in the orbitofrontal cortex and showed that the expression of synapse-related genes belonging to the BDNF network was downregulated with age as well [131]. Among the mechanisms that may affect the BDNF system during aging, an abnormal activation of the immune/inflammatory system is thought as an important candidate. Indeed, it is well known that the inflammatory response may affect neuroplasticity during development and adulthood [132]. Moreover, during aging, the immune system undergoes a dysregulation that leads to a chronic systemic inflammation, with increased levels of cytokines, chemokines, proinflammatory enzymes, and transcription factors [133, 134].

The "inflammaging" state does not rule out the brain, as the peripheral circulating small molecules-such as cytokines-can penetrate the CNS through the BBB inducing a cerebral state of neuroinflammation that can be further amplified by the activation of microglia [135]. In this context, it has been demonstrated that the activity of macrophages is specifically modified during aging, suggesting also a possible 


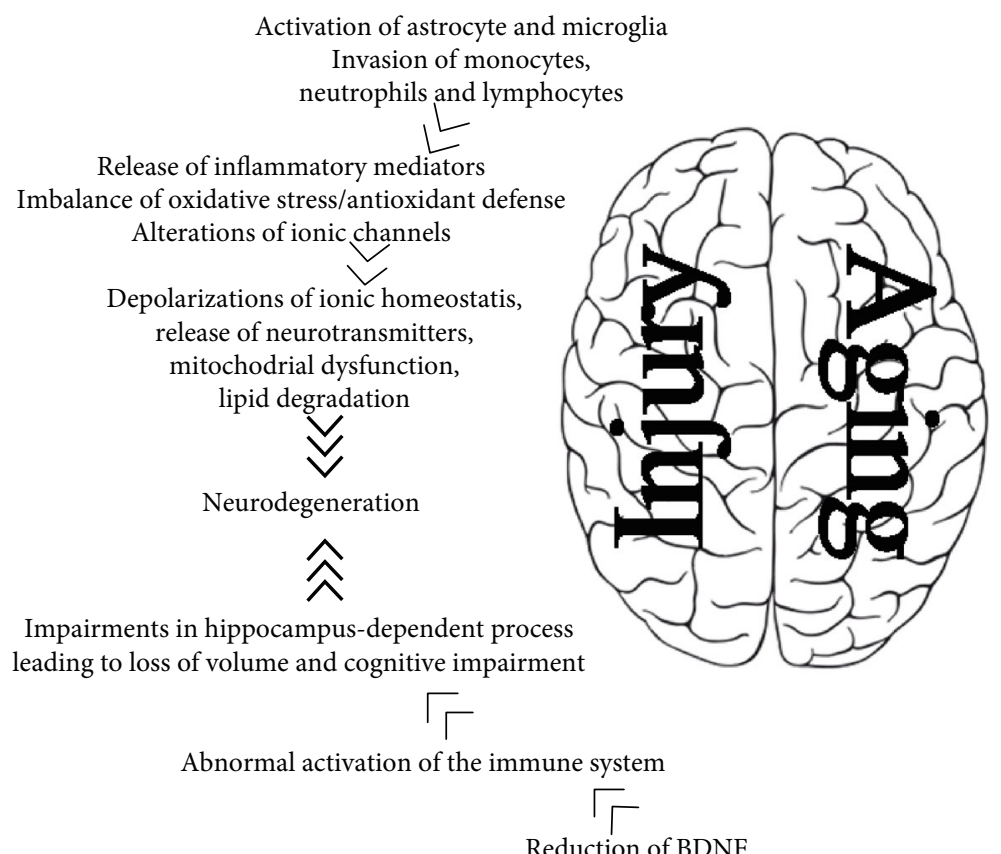

Figure 1: Contribution of inflammation, oxidative damage, and reduction in NT levels to neurodegeneration in aged brain after injury.

role for oxidative stress $[136,137]$. Under physiological conditions, microglia cells are in an apparent resting state in which they actively survey the CNS environment, ready to intervene when a detrimental stimulus occurs. Specifically, they undergo the activation state, with morphological changes and production of cytokines and of proliferative and macrophagic factors [138] following-when the threat (infection or damage) has been removed-to another state, characterized by a gene profile able to promote tissue repair and reconstruction, through the production of antiinflammatory cytokines, growth factors, and NTs such as BDNF [139]. During aging, microglia cells undergo a series of modification such as telomere shortening and cellular dystrophy, which lead to its senescence. In a postmortem study, Streit et al. observed significantly more dystrophic changes in microglia of aged individuals (68-year-old) than in the younger ones (38-year-old) [140]. Interestingly, it has been described that dystrophic or senescent microglia might undergo age-dependent degeneration losing its neuroprotective functions, thus increasing the risk of developing a neurodegenerative disease [141]. Using flow cytometry in mice, Ritzel et al. identified a significant population of side scatter-high microglia in the aged brain that display functional abnormalities when compared to young microglia, including higher production of ROS and proinflammatory cytokines, increased mitochondrial content, and poor phagocytic ability [142]. Furthermore, aged microglia cells adopt a proinflammatory state due to a decrease in the resting signalling by neurons and astrocytes [143]. As a result, external stimuli (e.g., stress, trauma, and infection) can easily switch the aged brain into a state of mild chronic neuroinflammation, making the brain more prone to apoptotic signalling [144-146], leading to loss of volume and cognitive impairment [147] (Figure 1).
In particular, preclinical studies demonstrated that elevated hippocampal levels of IL-1 $\beta$ impair the performances in behavioural paradigms commonly used to examine hippocampus-dependent memory [148, 149]. Numerous studies in rodents confirmed these observations, demonstrating impairments in hippocampus-dependent contextual tasks following intraperitoneal (i.p.) [150] or intrahippocampal injection of IL-1 $\beta$ [151] and elevations in endogenous IL$1 \beta$ evoked by infections [150-152] or psychological and physical stressors $[153,154]$.

As previously mentioned, this aging-dependent lowgrade chronic inflammation is thought to contribute to the reduction of BDNF levels observed in the older population. Guan and Fang, in a preclinical study, demonstrated that a peripheral injection of lipopolysaccharide (LPS), a strong cytokine inducer, causes a reduction of the protein levels of BDNF in different cortical regions as well as in the hippocampus of adult rats [155]. These observations have been confirmed also in mice, where reduced protein levels of pro-BDNF, mature BDNF, and BDNF mRNA levels have been found in synaptosomes three days after the LPS i.p. injection [156]. A similar result was observed in aged animals five days after the inflammatory challenge. Specifically, Cortese et al. exposed aged rats to E. coli i.p. administration to induce a peripheral inflammatory response finding reduced levels of mature BDNF and TrkB activation in comparison to aged rats treated with vehicle as well as to young rats exposed to E. coli [157]. Furthermore, the central administration of a receptor antagonist for IL-1 simultaneously to the E. coli injection was able to block the observed reduction of BDNF [158], as well as the associated long-term memory impairment caused by the E. coli injection [159]. In line with these observations, the infusion of the proinflammatory cytokine IL- $1 \beta$ into the 
hippocampus decreased the induction of BDNF gene expression induced by contextual fear conditioning [158].

\section{Mechanisms of Neurodegeneration Associated with Endothelial Cell Dysfunction}

Vascular risk factors such as age, diabetes, hypertension, and hypercholesterolemia often overlap with neurodegenerative risk factors in older patients, and vascular dysfunction is recognized as a determinant in several neurodegenerative diseases such as $\mathrm{AD}$, cerebral amyloid angiopathy (CAA), $\mathrm{PD}$, and ALS [160-163]. The BBB integrity, as part of the neurovascular unit (NVU), is essential to maintain adequate brain perfusion and brain functionality and to preserve normal neurological functions. Oxidative stress plays a critical role also on pathological BBB impairment and on the cerebrovascular dysfunction observed in neurodegenerative diseases.

$\mathrm{AD}$ is characterized by an excessive deposition of $\mathrm{A} \beta$ protein that destabilizes vascular integrity, promoting vascular leakage. Loss of vessel integrity manifests with EC detachment from basal membrane, double-barreling of the vessel walls, and aneurysm formation. These events often result in blood extravasation to the perivascular space and in the initiation of an inflammatory response, which characterizes neurodegenerative diseases. Several studies have clearly shown that pathological concentrations, in the range of micromolar, of different $\mathrm{A} \beta$ peptides, in particular the shorter vasculotropic $A \beta_{1-40}$ variant and the $A \beta$ mutants, are associated with distinct hereditary phenotypes of CAA and impair angiogenesis and vascular maintenance by increasing cellular oxidative stress. The vascular damage induced by $\mathrm{A} \beta$ includes alteration of vascular tone, impairment of vascular remodelling, and loss of barrier functions, as well as suppression of the intrinsic angiogenic properties of the endothelium.

Donnini et al. demonstrated that the $\mathrm{A} \beta_{1-40}$ peptide and its Dutch E22Q variant cause a premature senescent phenotype in ECs in both zebrafish embryos and human ECs [164]. $\mathrm{A} \beta_{1-40}$ peptide also causes mitochondrial impairment and reduces the aldehyde dehydrogenase-2 (ALDH2) detoxifying enzymatic activity in ECs, resulting in cell membrane disorganization and permeability defects [165]. Similarly, the $A \beta_{1-42}$ peptide has been reported to induce endoplasmic reticulum stress in rat brain ECs, subsequently leading to vascular derangements [166]. The molecular mechanisms of these multiple $\mathrm{A} \beta$-induced effects on ECs are complex and may include direct and indirect interaction with angiogenic growth factors, including vascular endothelial growth factor (VEGF) and fibroblast growth factor-2 (FGF-2).

FGF signalling is a prominent pathway involved in the maintenance of integrity in quiescent vasculature. Solito et al. showed that $\mathrm{A} \beta_{1-40}$ and its arctic E22G and Dutch E22Q variants downregulate FGF-2 production and FGF-2induced Akt activation. Moreover, $\mathrm{A} \beta_{1-40}$ and its variants inhibit FGF-2 binding to heparin and FGF receptor 1 phosphorylation, both in vivo and in vitro $[167,168]$. Of note, the disruption of vascular integrity by the $\mathrm{A} \beta_{1-40}$-induced deregulation of the FGF-2 signalling pathway can be rescued forcing overexpression of FGF-2 in ECs. Indeed, ECs overexpressing FGF-2 displayed extraordinary resistance to $\mathrm{A} \beta_{1-40^{-}}$ induced injuries. The FGF-2 mechanism responsible for reversing damages involves the downstream enhancement of Akt and the endothelial nitric oxide synthase (eNOS) activation [167].

Several studies showed that $A \beta$ also affects VEGF signalling. The VEGF receptor- 2 mRNA and the protein levels are significantly decreased after $\mathrm{A} \beta_{1-40}$, both in EC and in the brains of AD mouse models [169]. Patel et al. showed that $\mathrm{A} \beta_{1-42}$ inhibits VEGF-induced migration of ECs, competing with the VEGF for the binding with its receptor VEGFR [170]. Moreover, cell culture studies revealed that $\mathrm{A} \beta$ at pathological concentrations acts as a VEGF antagonist, inhibiting VEGF-induced tyrosine phosphorylation of VEGFR-2, as well as VEGF-stimulated phosphorylation of Akt and eNOS in ECs [170-172].

The $\mathrm{A} \beta$ precursor protein (APP) is expressed in several tissues and cells, such as the brain, kidney, platelets, and vascular endothelium of cerebral and peripheral blood vessels. Interestingly, several studies showed a vascular function of APP and/or A $\beta$ on ECs [173]. In cultured cerebral and peripheral ECs, nanomolar (nM) concentrations, similar to the physiological level of either $\mathrm{A} \beta_{1-40}$ or $\mathrm{A} \beta_{1-42}$ peptides, promote angiogenesis by increasing growth, migration, and tube branching $[174,175]$. Thus, oxidative stress is induced in ECs by high concentrations of $\mathrm{A} \beta$ peptide, which accumulates in the vessels of $\mathrm{BBB}$ and in the brain parenchyma. However, physiological levels of $A \beta$ are also required for the endothelial homeostasis, and increasing evidence highlights in several organs the importance of APP and its metabolites in supporting the function of the vascular tissue [173, 176]. The evidence that clinical trials aimed at targeting $\mathrm{A} \beta$ with immunotherapy have failed and, in some cases, have been harmful recalls the physiological role of $\mathrm{A} \beta$ and its precursor protein APP in the vasculature. More studies are needed to elucidate why ECs express high levels of APP and $\mathrm{A} \beta$ and what the functional role of these molecules is at a vascular level.

As we know, oxidative stress and mitochondrial dysfunctions are key actors in neurodegenerative disease. The mitochondrial enzyme ALDH2 has been shown to have a critical role in the neurotoxic mechanisms of these pathologies [177-179]. The mitochondrial disorder may promote the production of ROS, which increases the susceptibility of the cell to oxidative stress. One of the consequences of excessive oxidative stress is the overproduction of toxic aldehydes by lipid peroxidation from the mitochondrial membranes. Reactive aldehyde accumulation may inhibit ALDH2 and trigger mitochondrial dysfunction leading to a higher aldehyde-induced damage in both vasculature and neural tissues. The ALDH superfamily plays a crucial role in many biological processes including development and detoxification pathways in the organism [180]. In particular, mitochondrial ALDH2 is crucial in the oxidative metabolism of toxic aldehydes in the brain, such as catecholaminergic metabolites (DOPAL and DOPEGAL) and 4-hydroxy-2nonenal (4-HNE), the principal product of the lipid peroxidation process [178]. Recent studies have demonstrated that inhibition of ALDH2 activity significantly impairs EC functions, promoting senescence [181-183]. Lack of ALDH2 
activity reduces cell proliferation and migration and increases cellular permeability in ECs. Although the mechanisms of action has not been fully elucidated, these studies suggest that the accumulation of endogenous reactive aldehydes such as 4-HNE and ROS production are the main causes of endothelial dysfunction [181, 182].

In $\mathrm{AD}$ and $\mathrm{PD}$, the increase of oxidative stress, in part due to the formation of $\mathrm{A} \beta$ plaques and NFTs, can also be attributed to a failure of the detoxifying activity of ALDH2. This hypothesis is supported by the correlation between ALDH2 loss-of-function mutations and a higher incidence of $\mathrm{AD}$ [180]. Moreover, ALDH2 knockout mouse models exhibit both neuronal and vascular pathological changes associated with $\mathrm{AD}[183,184]$. In turn, A $\beta$ peptide toxicity can also impair mitochondrial ALDH2 activity [165]. Interestingly, this study shows that activation of ALDH2 has a protective role in endothelium against $\mathrm{A} \beta_{1-40}$ insult [165]. Treatment with ALDH2-specific-activator, Alda-1, significantly protects mitochondria function and reduces neuronal cell death in animal models of parkinsonism [178, 180, 185]. Due to its crucial role in maintenance of mitochondrial normal function, the use of ALDH2 activators would protect both vessels and neurons from neurotoxicity; thus, ALDH2 activation may represent a therapeutic target to treat neurodegenerative diseases.

\section{Advanced Glycation Endproducts Mediated Neurotoxicity and Their Influence on Redox Metabolism}

Neurodegeneration-mediated neurotoxicity can be induced by glycation reactions. Early glycation adducts mainly consist in Amadori products generated by the rearrangement of a Schiff base, resulting from the reversible reaction between a carbonyl group and protein amino group, mainly from lysine or arginine residues [186]. Even though the formation of Schiff bases is a reversible process, early glycation adducts can further rearrange through cyclization, oxidation, dehydration, or condensation reactions, leading to irreversibly bound adducts known as advanced glycation end-products (AGEs) $[187,188]$ often responsible for protein cross-links [189]. Since glycation is a nonenzymatic process, proteins characterized by a slow turnover are those that more easily accumulate AGEs [187]. In human tissues, AGE formation was first studied in relation to high blood sugar levels and diabetes, but more recently, other compounds such as glyceraldehyde, glycolaldehyde, glyoxal, and methylglyoxal have been recognized responsible for glycation reactions [190].

Methylglyoxal (MG), an a-ketoaldehyde, can occur as glycolysis by-product, but it is also present in foods (especially cooked and baked), beverages (mainly those fermented), and cigarette smoke, and it is considered the most potent precursor of AGE formation [191, 192]. In fact, it results 20,000 times more reactive than glucose in glycation reaction [193]. More than 20 different AGEs have been identified in foods and in human tissues. The most important ones are represented by pyrraline, pentosidine, carboxymethyl-lysine (CML), carboxyethyl-lysine (CEL), and methylglyoxal-lysine dimer (MOLD) [194, 195]. Due to MG and other carbonyl reactivity and toxicity, eukaryotic organisms have developed specific enzymes to detoxify them. The glyoxalase system, in fact, is composed of glyoxalases I and II and combines $\alpha$-ketoaldehydes to GSH to produce D-hydroxyacids [196]. Other enzymes and proteins contribute to counteract glycation; indeed, fructosamine-3-kinase catalyses fructosamine phosphorylation determining protein deglycation [197], and aldose reductase contributes to $\alpha$-oxoaldehyde reduction [198].

Beside diabetic complications, AGE accumulation in blood and tissues has been related to many chronic and degenerative diseases, such as neurodegenerative and cardiovascular diseases, atherosclerosis, and cancer, to induce cell signalling impairment, oxidative stress, and inflammation, as well as protein aggregation and cross-links [16]. In this context, AGE accumulation, oxidative stress, and inflammation are related to AGE ability to bind specific receptors called RAGE. Indeed, the activation of the AGE pathway can deregulate gene transcription, the signalling between cells and the extracellular matrix, and blood proteins, leading them to bind to RAGE on macrophages that, in turn, increase the release of growth factors and proinflammatory cytokines [199].

RAGE belongs to the immunoglobulin superfamily and is found in numerous tissues such as cardiac, vascular, pulmonary, and brain tissues. Moreover, their expression increases during aging, cancer, cardiovascular diseases, $\mathrm{AD}, \mathrm{PD}$, and other neurodegenerative diseases [200-205]. Although they were first described as AGE binding receptors, many other ligands have been discovered, such as S100 family molecules as well as high-mobility group protein 1 , known to be involved in inflammation and $\mathrm{A} \beta$ aggregation processes [206-208].

As soon as AGEs and other ligands accumulate, RAGE expression is induced [209] and elevated levels have been described in all the aforementioned pathological conditions and aging [203, 204].

AGE-RAGE binding activates numerous signalling pathways related to inflammation, oxidative stress, and apoptosis. RAGE activation has been demonstrated to induce NF- $\kappa$ B, which in turn is responsible for an increased expression of proinflammatory cytokines [210] and for the activation of the MAPK signalling pathway through the phosphorylation of extracellular signal-regulated kinases (ERK1/2), p38, and JNK, leading to inflammation, proliferation, and apoptosis [211]. Moreover, AGE-RAGE binding results in oxidative stress by the induction of the prooxidant enzyme NADPH oxidase (NOX2) [212]. RAGE is not the only group of receptors able to bind AGEs. In fact, AGER1-3 are involved in AGE detoxification by binding them on the cell surface and regulating their endocytosis to reduce oxidative stress, RAGE, and inflammation [213]. Interestingly AGERs are downregulated in many chronic diseases and in the presence of high AGE concentration $[214,215]$.

It is well known that AGE accumulation and oxidative stress play a central role in the pathogenesis of neurodegenerative diseases [216]. The brain, despite its high metabolic rate and oxygen consumption, is characterized by poor 
antioxidant defences; indeed, it presents weak expression of antioxidant enzymes as well as low levels of GSH and other antioxidants [217]. These aspects make the brain particularly prone to oxidative damage. In this context, AGEs play a dual role, since their formation is increased in oxidative conditions and because they promote oxidative stress [218]. AGE accumulation has been observed in brains affected by $\mathrm{AD}$ and PD as well as other neurodegenerative disorders [219]. Both $\mathrm{A} \beta$ plaques and NFT present AGE-induced protein cross-links, and $\mathrm{A} \beta$ aggregation is accelerated and stabilized in the presence of AGEs [220]. Besides their role in the stabilization of both $\mathrm{A} \beta$ and NFT, AGEs have been implicated also in their formation. Ko et al. demonstrated that AGEs induce APP expression, and also, glycated tau protein induces oxidative stress $[221,222]$. Moreover, $A \beta$ has been recognized as a RAGE ligand; $\mathrm{A} \beta$-RAGE binding contributes to the disease progression by inducing neuroinflammation and oxidative stress [223]. AGEs have been demonstrated to contribute also to the aggregation of $\alpha$-synuclein, a protein rich in lysine residues, to form Lewy bodies, a well-known biomarker of PD (Figure 2) [224, 225].

Beside pharmacological approaches, mainly focused on targeting RAGE $[223,226]$, a natural substance approach appears promising. Vitamin $\mathrm{B} 1$, being a coenzyme of transketolase, contributes to its activity and reduces the accumulation of glycolytic intermediates responsible for glycation's reactions [227]. Some flavonoids and other polyphenols have been proposed as safe candidates to delay the progression of AGE-mediated inflammatory diseases [228]. Some polyphenol-rich extracts, such as pomegranate, have been demonstrated to inhibit glycation or to trap MG in cell-free in vitro systems [229, 230].

Epigallocatechin gallate (EGCG) demonstrated to exert protective effects in vitro against AGE toxicity in neuronal cells. Lee and Lee showed, in SH-SY5Y cell culture, that 5$10 \mu \mathrm{M}$ of EGCG treatment counteracts oxidative stress, by inducing superoxide dismutase (SOD) and catalase (CAT), decreases MG levels and AGE formation, and downregulates RAGE expression [231]. In an in vivo rat model of $\mathrm{AD}$, resveratrol (Res) has been found able to decrease RAGE expression at the hippocampus level and to exert anti-inflammatory effects as demonstrated by the decrease of NF- $\kappa \mathrm{B}$ protein expression [232]. Other studies have related Res antiinflammatory properties to the induction of sirtuin 1 (SIRT1) protein, as demonstrated by Wang et al. in an in vivo rat model of AD. In SH-SY5Y cell culture, Res treatment counteracts oxidative stress and apoptosis induced by AGEs [201, 233, 234]. Recently, quercetin has been demonstrated to counteract dietary AGE-induced cognitive impairment in old ICR mice by inhibiting ERK1/2 and tau protein phosphorylation [235]. Angeloni et al. demonstrated that sulforaphane (an isothiocyanate from Brassica vegetables) protects SH-SY5Y neuronal cells against MG-induced damage by inhibiting the activation of caspase- 3 enzyme and reducing the phosphorylation of ERK1/2, JNK, and p38 signalling pathways.

Moreover, sulforaphane was able to counteract oxidative stress and to increase intracellular GSH levels and the expression, and activity, of glyoxalase $1[236,237]$. Bioactive sub-

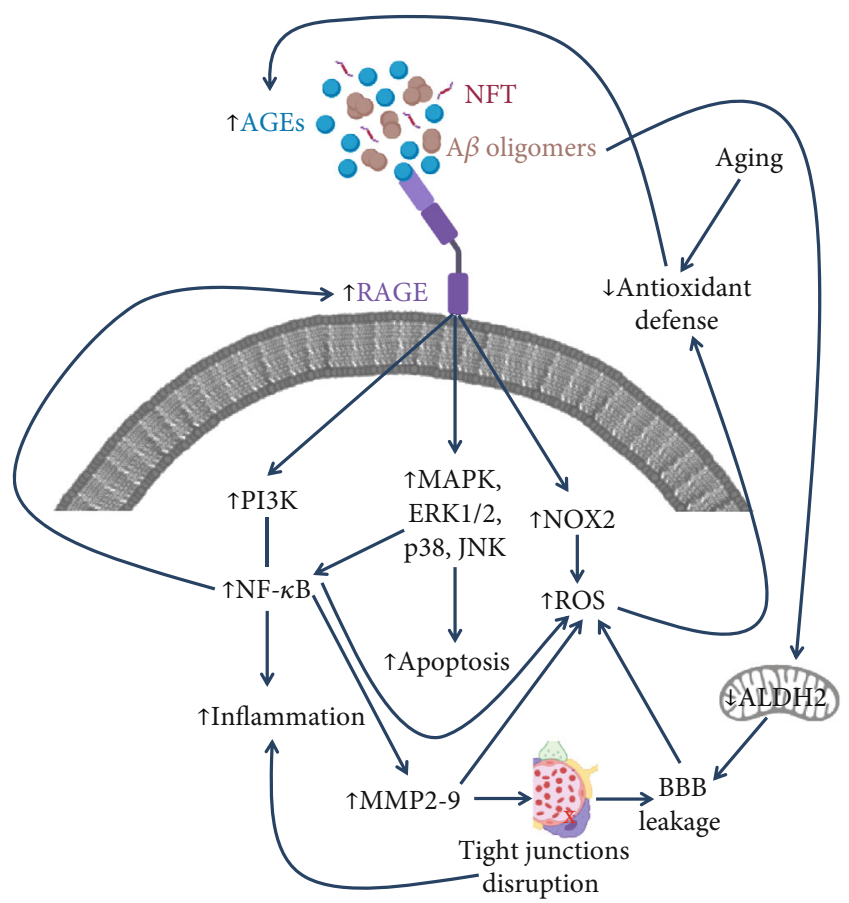

FIGURE 2: The vicious circle of the principal pathways involved in RAGE activation. AGE-RAGE binding activates different signalling pathways, in particular MAPK, PI3K, and NOX2, inducing inflammation, apoptosis, and oxidative stress. Moreover, the increased levels of NF- $\kappa \mathrm{B}$ induced the expression of RAGEs. The inflammatory response is also enhanced by the disruption of tight junctions at NVU that compromises also the BBB integrity. Oxidative stress is increased also by the high level of NF- $\kappa \mathrm{B}$ and by the consequent increment of MMP2-9. In aging, elevated ROS levels are not efficiently counteracted by endogenous antioxidative defences, and, as a consequence, AGE formation is increased. AGEs not only stabilize $\mathrm{A} \beta$ oligomers and NFT but also increase their formation. In addition, $\mathrm{A} \beta$ oligomers can also bind RAGE and activate the inflammatory/oxidative cascade. Finally, $\mathrm{A} \beta$ oligomers can trigger the impairment of mitochondrial ALDH2, leading to endothelial dysfunction and BBB leakage.

stances from Olea europaea, such as oleocanthal and hydroxytyrosol, are able to counteract the glycation processes [238, 239]; moreover, oleocanthal treatment improves GSH intracellular content and counteracts oxidative stress in neuron-like cell culture [240]. Recently, Angeloni et al. analysed the relationship between oleocanthal and $\mathrm{AD}$ suggesting that, besides its effects to interfere with tau protein hyperphosphorylation and aggregation and its ability to induce $\mathrm{A} \beta$ efflux and clearance, it might counteract AD's progression by reducing glycation in the brain, thanks to its positive effect on the GSH level, and to its ability to decrease oxidative stress [241].

Regardless of neurodegenerative diseases, the possibility to counteract the glycation processes and AGEs' toxicity using bioactive substances has recently been corroborated by the fact that activators of the Nrf2 signalling pathway have been able to induce the expression of genes involved in carbonyl stress resistance. It has recently been shown in $\mathrm{SH}$ SY5Y cell cultures that the activation of Nrf2 by carnosic acid 
causes an increase in the expression of factors involved in the synthesis of GSH and allows the detoxification of MG through the glyoxalase system, thus protecting the cells from MG-induced carbonyl stress [242].

In the light of these perspectives, it is now possible to speculate that the aforementioned protective effects of natural bioactive molecules against glycation and AGE's toxicity might be, at least in part, due to the modulation of $\mathrm{Nrf} 2$ as a key regulator of the inflammatory response and the oxidative damage related to neurodegeneration.

\section{Conclusions}

Neurodegenerative diseases have shown to share similar features. Although they have not been well characterized yet, oxidative stress, inflammation, excitotoxicity, and neuronal loss seem closely related in the evolution and progression of both chronic and acute conditions. Because of the high rate of oxygen consumption and the low detoxification mechanisms, the brain is an organ extensively exposed to oxidative stress [243]. The complex structure and functions of the brain still do not permit to clearly describe how neurodegeneration could evolve. The urgent need to study the intricate molecular mechanisms behind the onset and progression of neurodegenerative disease appears undeniable, in order to design more effective therapeutic strategies.

In this scenario, an intervention able to slow down or arrest the evolution of pathology could be the keystone in the treatment of these pathologies. A neuroprotective strategy interfering with the inflammatory response and oxidative stress may modulate positively the progressive impairment of the patients' quality of life. Neuroprotection could work in synergy with the endogenous defences, quenching ROS formation or restoring the antioxidant GSH system and its related enzymes and not less important slowing down the progressive neuronal death.

In the present review, we describe the complex network of molecular mechanisms underpinning acute and chronic neurodegeneration, focusing on the disturbance in redox homeostasis, as a common mechanism behind five pivotal risk factors: aging, oxidative stress, inflammation, glycation, and vascular injury. Aging is the primary unchangeable risk factor, and it is characterized by an extensive stress condition that enhances the loss of homeostasis, involving in particular the immune and inflammatory responses, which, in turn, increases oxidative stress generating a vicious circle [58].

Considering the complex multifactorial nature of neurodegenerative diseases, a preventive strategy able to simultaneously target multiple risk factors and disease mechanisms at an early stage is most likely to be effective to slow/halt the progression of neurodegenerative diseases. The holistic approach to neurodegeneration in the present review, taking into account and integrating several common risk factors, will provide critical insights that will most likely contribute to significant advances in the quest for new preventive pharmacological strategies to neurodegenerative disorders.

\section{Conflicts of Interest}

The authors declare that there is no conflict of interest regarding the publication of this paper.

\section{Authors' Contributions}

All authors equally contributed to this work.

\section{Acknowledgments}

This work was supported by the Ministero dell'Istruzione, dell'Università e della Ricerca (MIUR), PRIN 2015 (Prot. 20152HKF3Z).

\section{References}

[1] B. N. Dugger and D. W. Dickson, "Pathology of neurodegenerative diseases," Cold Spring Harbor Perspectives in Biology, vol. 9, no. 7, 2017.

[2] A. Tarozzi, C. Angeloni, M. Malaguti, F. Morroni, S. Hrelia, and P. Hrelia, "Sulforaphane as a potential protective phytochemical against neurodegenerative diseases," Oxidative Medicine and Cellular Longevity, vol. 2013, Article ID 415078, 10 pages, 2013.

[3] S. Majd, J. H. Power, and H. J. M. Grantham, "Neuronal response in Alzheimer's and Parkinson's disease: the effect of toxic proteins on intracellular pathways," BMC Neuroscience, vol. 16, no. 1, p. 69, 2015.

[4] J. Kim, H. J. Waldvogel, R. L. M. Faull, M. A. Curtis, and L. F. B. Nicholson, "The RAGE receptor and its ligands are highly expressed in astrocytes in a grade-dependant manner in the striatum and subependymal layer in Huntington's disease," Journal of Neurochemistry, vol. 134, no. 5, pp. 927-942, 2015.

[5] K. X. Liu, B. Edwards, S. Lee et al., "Neuron-specific antioxidant OXR1 extends survival of a mouse model of amyotrophic lateral sclerosis," Brain, vol. 138, no. 5, pp. 1167-1181, 2015.

[6] C. LoBue and C. M. Cullum, "Point/Counter-Point-Beyond the headlines: the actual evidence that traumatic brain injury is a risk factor for later-in-life dementia," Archives of Clinical Neuropsychology, vol. 35, no. 2, pp. 123-127, 2020.

[7] F. Licastro, S. Hrelia, E. Porcellini et al., "Peripheral inflammatory markers and antioxidant response during the postacute and chronic phase after severe traumatic brain injury," Frontiers in Neurology, vol. 7, 2016.

[8] C. Angeloni, C. Prata, F. Vieceli Dalla Sega, R. Piperno, and S. Hrelia, "Traumatic brain injury and NADPH oxidase: a deep relationship," Oxidative Medicine and Cellular Longevity, vol. 2015, Article ID 370312, 10 pages, 2015.

[9] A. Kahl, I. Blanco, K. Jackman et al., "Cerebral ischemia induces the aggregation of proteins linked to neurodegenerative diseases," Scientific Reports, vol. 8, no. 1, p. 2701, 2018.

[10] J. Zhou, J.-T. Yu, H.-F. Wang et al., "Association between stroke and Alzheimer's disease: systematic review and metaanalysis," Journal of Alzheimer's Disease, vol. 43, no. 2, pp. 479-489, 2014.

[11] B. R. Kummer, I. Diaz, X. Wu et al., "Associations between cerebrovascular risk factors and Parkinson disease," Annals of Neurology, vol. 86, no. 4, pp. 572-581, 2019. 
[12] S. T. Pendlebury, D. Poole, A. Burgess, J. Duerden, P. M. Rothwell, and for the Oxford Vascular Study, "APOE- $\varepsilon 4$ genotype and dementia before and after transient ischemic attack and Stroke," Stroke, vol. 51, no. 3, pp. 751-758, 2020.

[13] M. Castellazzi, A. Trentini, A. Romani et al., "Decreased arylesterase activity of paraoxonase-1 (PON-1) might be a common denominator of neuroinflammatory and neurodegenerative diseases," The International Journal of Biochemistry \& Cell Biology, vol. 81, Part B, pp. 356-363, 2016.

[14] J. V. Pluvinage and T. Wyss-Coray, "Systemic factors as mediators of brain homeostasis, ageing and neurodegeneration," Nature Reviews Neuroscience, vol. 21, no. 2, pp. 93$102,2020$.

[15] J. T. He, X. Zhao, L. Xu, and C. Y. Mao, "Vascular risk factors and Alzheimer's disease: blood-brain barrier disruption, metabolic syndromes, and molecular links," Journal of Alzheimer's Disease, vol. 73, no. 1, pp. 39-58, 2020.

[16] N. T. Moldogazieva, I. M. Mokhosoev, T. I. Mel'nikova, Y. B. Porozov, and A. A. Terentiev, "Oxidative stress and advanced lipoxidation and glycation end products (ALEs and AGEs) in aging and age-related diseases," Oxidative Medicine and Cellular Longevity, vol. 2019, Article ID 3085756, 14 pages, 2019.

[17] P. Giannoni, M. Arango-Lievano, I. D. Neves et al., "Cerebrovascular pathology during the progression of experimental Alzheimer's disease," Neurobiology of Disease, vol. 88, pp. 107-117, 2016.

[18] M. T. Golia, S. Poggini, S. Alboni et al., "Interplay between inflammation and neural plasticity: both immune activation and suppression impair LTP and BDNF expression," Brain, Behavior, and Immunity, vol. 81, pp. 484-494, 2019.

[19] L. Li, L. Dong, Z. Xiao et al., "Integrated analysis of the proteome and transcriptome in a MCAO mouse model revealed the molecular landscape during stroke progression," Journal of Advanced Research, vol. 24, pp. 13-27, 2020.

[20] N. Borjini, S. Sivilia, A. Giuliani et al., "Potential biomarkers for neuroinflammation and neurodegeneration at short and long term after neonatal hypoxic-ischemic insult in rat," Journal of Neuroinflammation, vol. 16, no. 1, p. 194, 2019.

[21] D. Scarabino, M. Peconi, E. Broggio et al., "Relationship between proinflammatory cytokines (Il-1beta, Il-18) and leukocyte telomere length in mild cognitive impairment and Alzheimer's disease," Experimental Gerontology, vol. 136, p. 110945, 2020.

[22] Q. Zeng, W. Lian, G. Wang, M. Qiu, L. Lin, and R. Zeng, "Pterostilbene induces Nrf2/HO-1 and potentially regulates NF- $\kappa \mathrm{B}$ and JNK-Akt/mTOR signaling in ischemic brain injury in neonatal rats," Biotech, vol. 10, no. 5, p. 192, 2020.

[23] R. L. Jayaraj, S. Azimullah, R. Beiram, F. Y. Jalal, and G. A. Rosenberg, "Neuroinflammation: friend and foe for ischemic stroke," Journal of Neuroinflammation, vol. 16, no. 1, p. 142, 2019.

[24] M. E. D. S. Rodrigues, M. C. Houser, D. I. Walker et al., “Targeting soluble tumor necrosis factor as a potential intervention to lower risk for late-onset Alzheimer's disease associated with obesity, metabolic syndrome, and type 2 diabetes," Alzheimer's Research \& Therapy, vol. 12, no. 1, 2020.

[25] A. Csiszar, A. Yabluchanskiy, A. Ungvari, Z. Ungvari, and S. Tarantini, "Overexpression of catalase targeted to mitochondria improves neurovascular coupling responses in aged mice," GeroScience, vol. 41, no. 5, pp. 609-617, 2019.
[26] T. Nyunt, M. Britton, K. Wanichthanarak et al., "Mitochondrial oxidative stress-induced transcript variants of ATF3 mediate lipotoxic brain microvascular injury," Free Radical Biology and Medicine, vol. 143, pp. 25-46, 2019.

[27] P. Toth, S. Tarantini, Z. Springo et al., “Aging exacerbates hypertension-induced cerebral microhemorrhages in mice: role of resveratrol treatment in vasoprotection," Aging Cell, vol. 14, no. 3, pp. 400-408, 2015.

[28] Z. Ungvari, L. Bailey-Downs, T. Gautam et al., "Age-associated vascular oxidative stress, Nrf2 dysfunction, and NF- $\kappa$ B activation in the nonhuman primate Macaca mulatta," The Journals of Gerontology Series A: Biological Sciences and Medical Sciences, vol. 66A, no. 8, pp. 866-875, 2011.

[29] E. B. Manukhina, H. F. Downey, X. Shi, and R. T. Mallet, "Intermittent hypoxia training protects cerebrovascular function in Alzheimer's disease," Experimental Biology and Medicine, vol. 241, no. 12, pp. 1351-1363, 2016.

[30] F. Xu, Y. Liu, X. Zhu et al., "Protective effects and mechanisms of vaccarin on vascular endothelial dysfunction in diabetic angiopathy," International Journal of Molecular Sciences, vol. 20, no. 18, p. 4587, 2019.

[31] F. Sivandzade, S. Prasad, A. Bhalerao, and L. Cucullo, "NRF2 and NF- $\kappa$ B interplay in cerebrovascular and neurodegenerative disorders: Molecular mechanisms and possible therapeutic approaches," Redox Biology, vol. 21, p. 101059, 2019.

[32] A. C. Ellis, T. Dudenbostel, J. L. Locher, and K. Crowe-White, "Modulating oxidative stress and inflammation in elders: the MOXIE study," Journal of Nutrition in Gerontology and Geriatrics, vol. 35, no. 4, pp. 219-242, 2016.

[33] P. Fattoretti, M. Malavolta, P. Fabbietti et al., "Oxidative stress in elderly with different cognitive status: my mind project," Journal of Alzheimer's Disease, vol. 63, no. 4, pp. 14051414, 2018.

[34] S. Emrani, M. Lamar, C. C. Price et al., "Alzheimer's/vascular spectrum dementia: classification in addition to diagnosis," Journal of Alzheimer's Disease, vol. 73, no. 1, pp. 63-71, 2020.

[35] A. M. Wennberg, J. L. Whitwell, N. Tosakulwong et al., "The influence of tau, amyloid, alpha-synuclein, TDP-43, and vascular pathology in clinically normal elderly individuals," $\mathrm{Neu}$ robiology of Aging, vol. 77, pp. 26-36, 2019.

[36] Y. Hou, X. Dan, M. Babbar et al., "Ageing as a risk factor for neurodegenerative disease," Nature Reviews Neurology, vol. 15, no. 10, pp. 565-581, 2019.

[37] I. Gkikas, D. Petratou, and N. Tavernarakis, "Longevity pathways and memory aging," Frontiers in Genetics, vol. 5, p. 155, 2014.

[38] B. A. Berkowitz, R. H. Podolsky, K. L. Childers et al., “Agerelated murine hippocampal CA1 laminae oxidative stress measured in vivo by QUEnch-assiSTed (QUEST) MRI: impact of isoflurane anesthesia," GeroScience, vol. 42, no. 2, pp. 563-574, 2020.

[39] N. A. Bishop, T. Lu, and B. A. Yankner, "Neural mechanisms of ageing and cognitive decline," Nature, vol. 464, no. 7288, pp. 529-535, 2010.

[40] J. H. Neltner, E. L. Abner, G. A. Jicha et al., "Brain pathologies in extreme old age," Neurobiology of Aging, vol. 37, pp. 1-11, 2016.

[41] S. Tsartsalis, A. Xekardaki, P. R. Hof, E. Kövari, and C. Bouras, "Early Alzheimer-type lesions in cognitively normal subjects," Neurobiology of Aging, vol. 62, pp. 34-44, 2018. 
[42] I. Liguori, G. Russo, F. Curcio et al., "Oxidative stress, aging, and diseases," Clinical Interventions in Aging, vol. 13, pp. 757-772, 2018.

[43] J. Sun, C. Steenbergen, and E. Murphy, "S-Nitrosylation: NOrelated redox signaling to protect against oxidative stress," Antioxidants \& Redox Signaling, vol. 8, no. 9-10, pp. 1693$1705,2006$.

[44] T. Nakamura and S. A. Lipton, "S-Nitrosylation of critical protein thiols mediates protein misfolding and mitochondrial dysfunction in neurodegenerative diseases," Antioxidants \& Redox Signaling, vol. 14, no. 8, pp. 1479-1492, 2011.

[45] C. A. Piantadosi and H. B. Suliman, "Transcriptional control of mitochondrial biogenesis and its interface with inflammatory processes," Biochimica et Biophysica Acta (BBA)-General Subjects, vol. 2012, p. 532, 2012.

[46] D.-H. Cho, T. Nakamura, J. Fang et al., "S-Nitrosylation of Drp1 mediates beta-amyloid-related mitochondrial fission and neuronal injury," Science, vol. 324, no. 5923, pp. 102105, 2009.

[47] S. L. Abtahi, R. Masoudi, and M. Haddadi, "The distinctive role of Tau and amyloid beta in mitochondrial dysfunction through alteration in Mfn2 and Drp1 mRNA levels: a comparative study in Drosophila melanogaster," Gene, vol. 754, p. 144854, 2020.

[48] W. Wang, F. Zhao, X. Ma, G. Perry, and X. Zhu, "Mitochondria dysfunction in the pathogenesis of Alzheimer's disease: recent advances," Molecular Neurodegeneration, vol. 15, no. 1, p. 30, 2020.

[49] M. S. Arrázola, E. Ramos-Fernández, P. Cisternas, D. Ordenes, and N. C. Inestrosa, "Wnt signaling prevents the $\mathrm{A} \beta$ oligomer-induced mitochondrial permeability transition pore opening preserving mitochondrial structure in hippocampal neurons," PLoS One, vol. 12, no. 1, article e0168840, 2017.

[50] M. Islam, "Oxidative stress and mitochondrial dysfunctionlinked neurodegenerative disorders," Neurological Research, vol. 39, no. 1, pp. 73-82, 2017.

[51] D. Antequera, T. Vargas, C. Ugalde et al., "Cytoplasmic gelsolin increases mitochondrial activity and reduces $\mathrm{A} \beta$ burden in a mouse model of Alzheimer's disease," Neurobiology of Disease, vol. 36, no. 1, pp. 42-50, 2009.

[52] W.-L. Zhu, J.-Y. Zheng, W.-W. Cai et al., "Ligustilide improves aging-induced memory deficit by regulating mitochondrial related inflammation in SAMP8 mice," Aging, vol. 12, no. 4, pp. 3175-3189, 2020.

[53] X. Kuang, H. J. Zhou, A. H. Thorne, X. N. Chen, L. J. Li, and J. R. Du, "Neuroprotective effect of ligustilide through induction of $\alpha$-secretase processing of both APP and Klotho in a mouse model of Alzheimer's disease," Frontiers in Aging Neuroscience, vol. 9, 2017.

[54] S. Wu, N. Wang, J. Li et al., "Ligustilide ameliorates the permeability of the blood-brain barrier model in vitro during oxygen-glucose deprivation injury through HIF/VEGF pathway," Journal of Cardiovascular Pharmacology, vol. 73, no. 5, pp. 316-325, 2019.

[55] F. Morroni, G. Sita, A. Tarozzi, R. Rimondini, and P. Hrelia, "Early effects of $A \beta 1-42$ oligomers injection in mice: involvement of PI3K/Akt/GSK3 and MAPK/ERK1/2 pathways," Behavioural Brain Research, vol. 314, pp. 106-115, 2016.

[56] F. Morroni, G. Sita, A. Graziosi et al., "Protective effects of 6(methylsulfinyl) hexyl isothiocyanate on A $\beta 1-42$-induced cognitive deficit, oxidative stress, inflammation, and apoptosis in mice," International Journal of Molecular Sciences, vol. 19, no. 7, p. 2083, 2018.

[57] F. Morroni, G. Sita, A. Graziosi et al., "PQM130, a novel feruloyl-donepezil hybrid compound, effectively ameliorates the cognitive impairments and pathology in a mouse model of Alzheimer's disease," Frontiers in Pharmacology, vol. 10, p. $658,2019$.

[58] M. Fuente and J. Miquel, "An update of the oxidationinflammation theory of aging: the involvement of the immune system in oxi-inflamm-aging," Current Pharmaceutical Design, vol. 15, no. 26, pp. 3003-3026, 2009.

[59] M. Baierle, S. N. Nascimento, A. M. Moro et al., "Relationship between inflammation and oxidative stress and cognitive decline in the institutionalized elderly," Oxidative Medicine and Cellular Longevity, vol. 2015, 12 pages, 2015.

[60] F. Morroni, G. Sita, A. Graziosi et al., "Neuroprotective effect of caffeic acid phenethyl ester in a mouse model of Alzheimer's disease involves Nrf2/HO-1 pathway," Aging and Disease, vol. 9, no. 4, pp. 605-622, 2018.

[61] F. Revel, T. Gilbert, S. Roche et al., "Influence of oxidative stress biomarkers on cognitive decline," Journal of Alzheimer's Disease, vol. 45, no. 2, pp. 553-560, 2015.

[62] S. I. Mota, R. O. Costa, I. L. Ferreira et al., "Oxidative stress involving changes in Nrf2 and ER stress in early stages of Alzheimer's disease," Biochimica et Biophysica Acta (BBA) Molecular Basis of Disease, vol. 1852, no. 7, pp. 1428-1441, 2015.

[63] D. A. Butterfield and J. N. Keller, "Antioxidants and antioxidant treatment in disease," Biochimica et Biophysica Acta (BBA) - Molecular Basis of Disease, vol. 1822, no. 5, p. 615, 2012.

[64] P. Deshmukh, S. Unni, G. Krishnappa, and B. Padmanabhan, "The Keap 1-Nrf2 pathway: promising therapeutic target to counteract ROS-mediated damage in cancers and neurodegenerative diseases," Biophysical Reviews, vol. 9, no. 1, pp. 41-56, 2017.

[65] J.-J. Qin, X.-D. Cheng, J. Zhang, and W.-D. Zhang, "Dual roles and therapeutic potential of Keap 1-Nrf2 pathway in pancreatic cancer: a systematic review," Cell Communication and Signaling, vol. 17, no. 1, p. 121, 2019.

[66] A. I. Rojo, M. Pajares, P. Rada et al., "NRF2 deficiency replicates transcriptomic changes in Alzheimer's patients and worsens APP and TAU pathology," Redox Biology, vol. 13, pp. 444-451, 2017.

[67] D. J. Loane and A. I. Faden, "Neuroprotection for traumatic brain injury: translational challenges and emerging therapeutic strategies," Trends in Pharmacological Sciences, vol. 31, no. 12, pp. 596-604, 2010.

[68] T. K. McIntosh, D. H. Smith, D. F. Meaney, M. J. Kotapka, T. A. Gennarelli, and D. I. Graham, "Neuropathological sequelae of traumatic brain injury: relationship to neurochemical and biomechanical mechanisms," Laboratory Investigation, vol. 74, pp. 315-342, 1996.

[69] N. T. Gentile and T. K. McIntosh, "Antagonists of excitatory amino acids and endogenous opioid peptides in the treatment of experimental central nervous system injury," Annals of Emergency Medicine, vol. 22, no. 6, pp. 1028-1034, 1993.

[70] A. Faden, P. Demediuk, S. Panter, and R. Vink, "The role of excitatory amino acids and NMDA receptors in traumatic brain injury," Science, vol. 244, no. 4906, pp. 798-800, 1989. 
[71] Y. Xiong, Q. Gu, P. L. Peterson, J. P. Muizelaar, and C. P. Lee, "Mitochondrial dysfunction and calcium perturbation induced by traumatic brain injury," Journal of Neurotrauma, vol. 14, no. 1, pp. 23-34, 1997.

[72] A. G. Yakovlev, S. M. Knoblach, L. Fan, G. B. Fox, R. Goodnight, and A. I. Faden, "Activation of CPP32-like caspases contributes to neuronal apoptosis and neurological dysfunction after traumatic brain injury," The Journal of Neuroscience, vol. 17, no. 19, pp. 7415-7424, 1997.

[73] E. D. Hall, M. R. Detloff, K. Johnson, and N. C. Kupina, "Peroxynitrite-mediated protein nitration and lipid peroxidation in a mouse model of traumatic brain injury," Journal of Neurotrauma, vol. 21, no. 1, pp. 9-20, 2004.

[74] M. C. Morganti-Kossmann, L. Satgunaseelan, N. Bye, and T. Kossmann, "Modulation of immune response by head injury," Injury, vol. 38, no. 12, pp. 1392-1400, 2007.

[75] M. Fatahzadeh and M. Glick, "Stroke: epidemiology, classification, risk factors, complications, diagnosis, prevention, and medical and dental management," Oral Surgery, Oral Medicine, Oral Pathology, Oral Radiology, and Endodontology, vol. 102, pp. 180-191, 2006.

[76] R. L. Sacco, S. E. Kasner, J. P. Broderick et al., "An updated definition of stroke for the 21st century," Stroke, vol. 44, no. 7, pp. 2064-2089, 2013.

[77] J. D. Easton, J. L. Saver, G. W. Albers et al., "Definition and evaluation of transient ischemic Attack," Stroke, vol. 40, no. 6, pp. 2276-2293, 2009.

[78] M. Mutinati, M. Pantaleo, M. Roncetti, M. Piccinno, A. Rizzo, and R. L. Sciorsci, "Oxidative stress in neonatology: a review," Reproduction in Domestic Animals, vol. 49, no. 1, pp. 7-16, 2014.

[79] K. Fluiter, A. L. Opperhuizen, B. P. Morgan, F. Baas, and V. Ramaglia, "Inhibition of the membrane attack complex of the complement system reduces secondary neuroaxonal loss and promotes neurologic recovery after traumatic brain injury in mice," The Journal of Immunology, vol. 192, no. 5, pp. 2339-2348, 2014.

[80] D. Davalos, J. Grutzendler, G. Yang et al., "ATP mediates rapid microglial response to local brain injury in vivo," Nature Neuroscience, vol. 8, no. 6, pp. 752-758, 2005.

[81] M. L. Block and J.-S. Hong, "Microglia and inflammationmediated neurodegeneration: multiple triggers with a common mechanism," Progress in Neurobiology, vol. 76, no. 2, pp. 77-98, 2005.

[82] D. Zhang, X. Hu, L. Qian, J. P. O'Callaghan, and J. S. Hong, "Astrogliosis in CNS pathologies: is there a role for microglia?," Molecular Neurobiology, vol. 41, no. 2-3, pp. 232-241, 2010.

[83] Z. Zhao, S. Alam, R. W. Oppenheim, D. M. Prevette, A. Evenson, and A. Parsadanian, "Overexpression of glial cell line-derived neurotrophic factor in the CNS rescues motoneurons from programmed cell death and promotes their long-term survival following axotomy," Experimental Neurology, vol. 190, no. 2, pp. 356-372, 2004.

[84] A. Schousboe and H. S. Waagepetersen, "Role of astrocytes in glutamate homeostasis: implications for excitotoxicity," Neurotoxicity Research, vol. 8, no. 3-4, pp. 221-225, 2005.

[85] H. Pivonkova and M. Anderova, "Altered homeostatic functions in reactive astrocytes and their potential as a therapeutic target after brain ischemic injury," Current Pharmaceutical Design, vol. 23, no. 33, 2018.
[86] A. G. Ceulemans, T. Zgavc, R. Kooijman, S. Hachimi-Idrissi, S. Sarre, and Y. Michotte, "The dual role of the neuroinflammatory response after ischemic stroke: modulatory effects of hypothermia," Journal of Neuroinflammation, vol. 7, no. 1, p. 74, 2010.

[87] M. Y. Martynov and E. I. Gusev, "Current knowledge on the neuroprotective and neuroregenerative properties of citicoline in acute ischemic stroke," Journal of Experimental Pharmacology, vol. 7, pp. 17-28, 2015.

[88] L. Huang, Z.-B. Wu, Q. ZhuGe et al., "Glial scar formation occurs in the human brain after ischemic stroke," International Journal of Medical Sciences, vol. 11, no. 4, pp. 344348, 2014.

[89] J. Y. Kim, J. Park, J. Y. Chang, S. H. Kim, and J. E. Lee, "Inflammation after Ischemic stroke: the role of leukocytes and glial cells," Experimental Neurobiology, vol. 25, no. 5, pp. 241-251, 2016.

[90] S. E. Lakhan, A. Kirchgessner, and M. Hofer, "Inflammatory mechanisms in ischemic stroke: therapeutic approaches," Journal of Translational Medicine, vol. 7, no. 1, 2009.

[91] R. Reyes, B. Cardeñes, Y. Machado-Pineda, and C. Cabañas, "Tetraspanin CD9: a key regulator of cell adhesion in the immune system," Frontiers in Immunology, vol. 9, 2018.

[92] C. Yang, K. E. Hawkins, S. Doré, and E. Candelario-Jalil, "Neuroinflammatory mechanisms of blood-brain barrier damage in ischemic stroke," American Journal of Physiology-Cell Physiology, vol. 316, no. 2, pp. C135-C153, 2019.

[93] L. Ramiro, A. Simats, T. García-Berrocoso, and J. Montaner, "Inflammatory molecules might become both biomarkers and therapeutic targets for stroke management," Therapeutic Advances in Neurological Disorders, vol. 11, 2018.

[94] A. Tuttolomondo, R. Pecoraro, and A. Pinto, "Studies of selective tnf inhibitors in the treatment of brain injury from stroke and trauma: a review of the evidence to date," Drug Design, Development and Therapy, vol. 8, pp. 2221-2239, 2014.

[95] M. Fang, L. Zhong, X. Jin et al., "Effect of inflammation on the process of stroke rehabilitation and poststroke depression," Frontiers in Psychiatry, vol. 10, 2019.

[96] J. J. O'Connor, "Targeting tumour necrosis factor- $\alpha$ in hypoxia and synaptic signalling," Irish Journal of Medical Science, vol. 182, no. 2, pp. 157-162, 2013.

[97] S. H. Yang, M. Lou, B. Luo, W. J. Jiang, and R. Liu, "Precision medicine for ischemic stroke, let us move beyond time is brain," Translational Stroke Research, vol. 9, no. 2, pp. 9395, 2018.

[98] S. H. Yang, M. Gangidine, T. A. Pritts, M. D. Goodman, and A. B. Lentsch, "Interleukin 6 mediates neuroinflammation and motor coordination deficits after mild traumatic brain injury and brief hypoxia in mice," Shock, vol. 40, no. 6, pp. 471-475, 2013.

[99] L. M. Crowe, C. Catroppa, F. E. Babl, J. V. Rosenfeld, and V. Anderson, "Timing of traumatic brain injury in childhood and intellectual outcome," Journal of Pediatric Psychology, vol. 37, no. 7, pp. 745-754, 2012.

[100] J. Donders and S. Warschausky, "Neurobehavioral outcomes after early versus late childhood traumatic brain injury," Journal of Head Trauma Rehabilitation, vol. 22, no. 5, pp. 296302, 2007. 
[101] M. T. Goodus, A. M. Guzman, F. Calderon, Y. Jiang, and S. W. Levison, "Neural stem cells in the immature, but not the mature, subventricular zone respond robustly to traumatic brain injury," Developmental Neuroscience, vol. 37, no. 1, pp. 29-42, 2015.

[102] V. Anderson, M. Spencer-Smith, R. Leventer et al., "Childhood brain insult: can age at insult help us predict outcome?," Brain, vol. 132, no. 1, pp. 45-56, 2009.

[103] M. R. Hoane, L. A. Lasley, and S. L. Akstulewicz, "Middle age increases tissue vulnerability and impairs sensorimotor and cognitive recovery following traumatic brain injury in the rat," Behavioural Brain Research, vol. 153, no. 1, pp. 189197, 2004.

[104] F. Sohrabji, "The impact of aging on ischemic stroke," Advances in Geroscience, pp. 161-196, Springer International Publishing, 2016.

[105] C. X. Shao, K. N. Roberts, W. R. Markesbery, S. W. Scheff, and M. A. Lovell, "Oxidative stress in head trauma in aging," Free Radical Biology and Medicine, vol. 41, no. 1, pp. 77-85, 2006.

[106] T. Satoh, A. Otsuka, E. Contassot, and L. E. French, "The inflammasome and IL- $1 \beta$ : implications for the treatment of inflammatory diseases," Immunotherapy, vol. 7, no. 3, pp. 243-254, 2015.

[107] V. Calabrese, A. Santoro, D. Monti et al., "Aging and Parkinson's Disease: Inflammaging, neuroinflammation and biological remodeling as key factors in pathogenesis," Free Radical Biology and Medicine, vol. 115, pp. 80-91, 2018.

[108] R. Crupi, D. Impellizzeri, M. Cordaro et al., "N-Palmitoylethanolamide prevents parkinsonian phenotypes in aged mice," Molecular Neurobiology, vol. 55, no. 11, pp. 84558472, 2018.

[109] A. Hald and J. Lotharius, "Oxidative stress and inflammation in Parkinson's disease: is there a causal link?," Experimental Neurology, vol. 193, no. 2, pp. 279-290, 2005.

[110] E. Fuchs and G. Flügge, "Adult neuroplasticity: more than 40 years of research,” Neural Plasticity, vol. 2014, Article ID 541870, 10 pages, 2014.

[111] M. V. Chao, "Neurotrophins and their receptors: a convergence point for many signalling pathways," Nature Reviews Neuroscience, vol. 4, no. 4, pp. 299-309, 2003.

[112] M. Mitre, A. Mariga, and M. V. Chao, "Neurotrophin signalling: novel insights into mechanisms and pathophysiology," Clinical Science, vol. 131, no. 1, pp. 13-23, 2017.

[113] S. Cohen-Cory, A. H. Kidane, N. J. Shirkey, and S. Marshak, "Brain-derived neurotrophic factor and the development of structural neuronal connectivity," Developmental Neurobiology, vol. 70, no. 5, pp. 271-288, 2010.

[114] E. J. Huang and L. F. Reichardt, "Neurotrophins: roles in neuronal development and function," Annual Review of Neuroscience, vol. 24, no. 1, pp. 677-736, 2001.

[115] T. Aid, A. Kazantseva, M. Piirsoo, K. Palm, and T. Timmusk, "Mouse and rat BDNF gene structure and expression revisited," Journal of Neuroscience Research, vol. 85, no. 3, pp. 525-535, 2007.

[116] Q. R. Liu, D. Walther, T. Drgon et al., "Human brain derived neurotrophic factor (BDNF) genes, splicing patterns, and assessments of associations with substance abuse and Parkinson's disease," American Journal of Medical Genetics. Part B, Neuropsychiatric Genetics, vol. 134B, no. 1, pp. 93-103, 2005.
[117] P. P. Pattabiraman, D. Tropea, C. Chiaruttini, E. Tongiorgi, A. Cattaneo, and L. Domenici, "Neuronal activity regulates the developmental expression and subcellular localization of cortical BDNF mRNA isoforms in vivo," Molecular and Cellular Neurosciences, vol. 28, no. 3, pp. 556-570, 2005.

[118] J. J. An, K. Gharami, G. Y. Liao et al., "Distinct role of long 3 ' UTR BDNF mRNA in spine morphology and synaptic plasticity in hippocampal neurons," Cell, vol. 134, no. 1, pp. 175-187, 2008.

[119] E. Tongiorgi and G. Baj, "Functions and mechanisms of BDNF mRNA trafficking," in Growth Factors and Psychiatric Disorders, pp. 136-147, Wiley, 2008.

[120] P. Kowiański, G. Lietzau, E. Czuba, M. Waśkow, A. Steliga, and J. Moryś, "BDNF: a key factor with multipotent impact on brain signaling and synaptic plasticity," Cellular and Molecular Neurobiology, vol. 38, no. 3, pp. 579-593, 2018.

[121] M. Baydyuk and B. Xu, "BDNF signaling and survival of striatal neurons," Frontiers in Cellular Neuroscience, vol. 8, p. $254,2014$.

[122] A. Gonzalez, G. Moya-Alvarado, C. Gonzalez-Billaut, and F. C. Bronfman, "Cellular and molecular mechanisms regulating neuronal growth by brain-derived neurotrophic factor," Cytoskeleton, vol. 73, no. 10, pp. 612-628, 2016.

[123] H. Park and M. M. Poo, "Neurotrophin regulation of neural circuit development and function," Nature Reviews Neuroscience, vol. 14, no. 1, pp. 7-23, 2013.

[124] J. Jaworski, S. Spangler, D. P. Seeburg, C. C. Hoogenraad, and M. Sheng, "Control of dendritic arborization by the Phosphoinositide-3'-Kinase-Akt-Mammalian target of rapamycin pathway," Journal of Neuroscience, vol. 25, no. 49, pp. 11300 11312, 2005.

[125] V. Kumar, M. X. Zhang, M. W. Swank, J. Kunz, and G. Y. Wu, "Regulation of dendritic morphogenesis by Ras-PI3K-AktmTOR and Ras-MAPK signaling pathways," Journal of Neuroscience, vol. 25, no. 49, pp. 11288-11299, 2005.

[126] L. F. Reichardt, "Neurotrophin-regulated signalling pathways," Philosophical Transactions of the Royal Society B: Biological Sciences, vol. 361, no. 1473, pp. 1545-1564, 2006.

[127] P. Brivio, M. S. Paladini, G. Racagni, M. A. Riva, F. Calabrese, and R. Molteni, "From healthy aging to frailty: in search of the underlying mechanisms," Current Medicinal Chemistry, vol. 26, no. 20, pp. 3685-3701, 2019.

[128] P. R. Hof, H. Duan, T. L. Page et al., "Age-related changes in GluR2 and NMDAR1 glutamate receptor subunit protein immunoreactivity in corticocortically projecting neurons in macaque and patas monkeys," Brain Research, vol. 928, no. 1-2, pp. 175-186, 2002.

[129] A. A. Ziegenhorn, O. Schulte-Herbrüggen, H. Danker-Hopfe et al., "Serum neurotrophins-A study on the time course and influencing factors in a large old age sample," Neurobiology of Aging, vol. 28, no. 9, pp. 1436-1445, 2007.

[130] K. I. Erickson, R. S. Prakash, M. W. Voss et al., "Brain-derived neurotrophic factor is associated with age-related decline in hippocampal volume," Journal of Neuroscience, vol. 30, no. 15 , pp. 5368-5375, 2010.

[131] H. Oh, D. A. Lewis, and E. Sibille, "The role of BDNF in agedependent changes of excitatory and inhibitory synaptic markers in the human prefrontal cortex," Neuropsychopharmacology, vol. 41, no. 13, pp. 3080-3091, 2016.

[132] F. Calabrese, A. C. Rossetti, G. Racagni, P. Gass, M. A. Riva, and R. Molteni, "Brain-derived neurotrophic factor: a bridge 
between inflammation and neuroplasticity," Frontiers in Cellular Neuroscience, vol. 8, 2014.

[133] C. Franceschi and J. Campisi, "Chronic inflammation (inflammaging) and its potential contribution to ageassociated diseases," The Journals of Gerontology Series A: Biological Sciences and Medical Sciences, vol. 69, Supplement 1, pp. S4-S9, 2014.

[134] H. Y. Chung, D. H. Kim, E. K. Lee et al., "Redefining chronic inflammation in aging and age-related diseases: proposal of the senoinflammation concept," Aging and Disease, vol. 10, no. 2, pp. 367-382, 2019.

[135] S. F. Maier, "Bi-directional immune-brain communication: Implications for understanding stress, pain, and cognition," Brain, Behavior, and Immunity, vol. 17, no. 2, pp. 69-85, 2003.

[136] E. S. Cannizzo, C. C. Clement, R. Sahu, C. Follo, and L. Santambrogio, "Oxidative stress, inflamm-aging and immunosenescence," Journal of Proteomics, vol. 74, no. 11, pp. 2313-2323, 2011.

[137] C. Sebastián, C. Herrero, M. Serra, J. Lloberas, M. A. Blasco, and A. Celada, "Telomere shortening and oxidative stress in aged macrophages results in impaired STAT5a phosphorylation," The Journal of Immunology, vol. 183, no. 4, pp. 23562364, 2009.

[138] C. A. Colton, "Heterogeneity of microglial activation in the innate immune response in the brain," Journal of Neuroimmune Pharmacology, vol. 4, no. 4, pp. 399-418, 2009.

[139] C. N. Parkhurst, G. Yang, I. Ninan et al., "Microglia promote learning-dependent synapse formation through brainderived neurotrophic factor," Cell, vol. 155, no. 7, pp. 15961609, 2013.

[140] W. J. Streit, N. W. Sammons, A. J. Kuhns, and D. L. Sparks, "Dystrophic microglia in the aging human brain," Glia, vol. 45 , no. 2, pp. 208-212, 2004.

[141] W. J. Streit, H. Braak, Q. S. Xue, and I. Bechmann, "Dystrophic (senescent) rather than activated microglial cells are associated with tau pathology and likely precede neurodegeneration in Alzheimer's disease," Acta Neuropathologica, vol. 118, no. 4, pp. 475-485, 2009.

[142] R. M. Ritzel, A. R. Patel, S. Pan et al., "Age- and locationrelated changes in microglial function," Neurobiology of Aging, vol. 36, no. 6, pp. 2153-2163, 2015.

[143] A. E. Cardona, E. P. Pioro, M. E. Sasse et al., "Control of microglial neurotoxicity by the fractalkine receptor," Nature Neuroscience, vol. 9, no. 7, pp. 917-924, 2006.

[144] R. N. Dilger and R. W. Johnson, "Aging, microglial cell priming, and the discordant central inflammatory response to signals from the peripheral immune system," Journal of Leukocyte Biology, vol. 84, no. 4, pp. 932-939, 2008.

[145] J. P. Godbout, J. Chen, J. Abraham et al., "Exaggerated neuroinflammation and sickness behavior in aged mice after activation of the peripheral innate immune system," The FASEB Journal, vol. 19, no. 10, pp. 1329-1331, 2005.

[146] A. Niraula, J. F. Sheridan, and J. P. Godbout, "Microglia priming with aging and stress," Neuropsychopharmacology, vol. 42, no. 1, pp. 318-333, 2017.

[147] R. von Bernhardi, L. Eugenín-von Bernhardi, and J. Eugenín, "Microglial cell dysregulation in brain aging and neurodegeneration," Frontiers in Aging Neuroscience, vol. 7, 2015.
[148] R. Morris, "Developments of a water-maze procedure for studying spatial learning in the rat," Journal of Neuroscience Methods, vol. 11, no. 1, pp. 47-60, 1984.

[149] R. G. Phillips and J. E. LeDoux, "Differential contribution of amygdala and hippocampus to cued and contextual fear conditioning," Behavioral Neuroscience, vol. 106, no. 2, pp. 274285, 1992.

[150] M. Gibertini, C. Newton, H. Friedman, and T. W. Klein, "Spatial learning impairment in mice infected with legionella pneumophila or administered exogenous interleukin-1- $\beta$," Brain, Behavior, and Immunity, vol. 9, no. 2, pp. 113-128, 1995.

[151] R. M. Barrientos, E. A. Higgins, J. C. Biedenkapp et al., "Peripheral infection and aging interact to impair hippocampal memory consolidation," Neurobiology of Aging, vol. 27, no. 5, pp. 723-732, 2006.

[152] J. Chen, J. B. Buchanan, N. L. Sparkman, J. P. Godbout, G. G. Freund, and R. W. Johnson, "Neuroinflammation and disruption in working memory in aged mice after acute stimulation of the peripheral innate immune system," Brain, Behavior, and Immunity, vol. 22, no. 3, pp. 301-311, 2008.

[153] A. C. Rossetti, M. Papp, P. Gruca et al., "Stress-induced anhedonia is associated with the activation of the inflammatory system in the rat brain: restorative effect of pharmacological intervention," Pharmacol. Res., vol. 103, pp. 1-12, 2016.

[154] C. R. Pugh, K. T. Nguyen, J. L. Gonyea et al., "Role of interleukin-1 beta in impairment of contextual fear conditioning caused by social isolation," Behavioural Brain Research, vol. 106, no. 1-2, pp. 109-118, 1999.

[155] Z. Guan and J. Fang, "Peripheral immune activation by lipopolysaccharide decreases neurotrophins in the cortex and hippocampus in rats," Brain, Behavior, and Immunity, vol. 20, no. 1, pp. 64-71, 2006.

[156] S. Schnydrig, L. Korner, S. Landweer et al., "Peripheral lipopolysaccharide administration transiently affects expression of brain-derived neurotrophic factor, corticotropin and proopiomelanocortin in mouse brain," Neuroscience Letters, vol. 429, no. 1, pp. 69-73, 2007.

[157] G. P. Cortese, R. M. Barrientos, S. F. Maier, and S. L. Patterson, "Aging and a peripheral immune challenge interact to reduce mature brain-derived neurotrophic factor and activation of TrkB, PLC 1, and ERK in hippocampal synaptoneurosomes," Journal of Neuroscience, vol. 31, no. 11, pp. 42744279, 2011.

[158] R. M. Barrientos, D. B. Sprunger, S. Campeau, L. R. Watkins, J. W. Rudy, and S. F. Maier, "BDNF mRNA expression in rat hippocampus following contextual learning is blocked by intrahippocampal IL- $1 \beta$ administration," Journal of Neuroimmunology, vol. 155, no. 1-2, pp. 119-126, 2004.

[159] M. G. Frank, R. M. Barrientos, A. M. Hein, J. C. Biedenkapp, L. R. Watkins, and S. F. Maier, "IL-1RA blocks E. coliinduced suppression of Arc and long-term memory in aged F344 $\times$ BN F1 rats," Brain, Behavior, and Immunity, vol. 24, no. 2, pp. 254-262, 2010.

[160] L. T. Grinberg, A. D. Korczyn, and H. Heinsen, "Cerebral amyloid angiopathy impact on endothelium," Experimental Gerontology, vol. 47, no. 11, pp. 838-842, 2012.

[161] E. A. Winkler, J. D. Sengillo, J. S. Sullivan, J. S. Henkel, S. H. Appel, and B. V. Zlokovic, "Blood-spinal cord barrier breakdown and pericyte reductions in amyotrophic lateral sclerosis," Acta Neuropathologica, vol. 125, no. 1, pp. 111-120, 2013. 
[162] H. M. Snyder, R. A. Corriveau, S. Craft et al., "Vascular contributions to cognitive impairment and dementia including Alzheimer's disease," Alzheimer's \& Dementia, vol. 11, no. 6, pp. 710-717, 2015.

[163] A. D. Korczyn, "Vascular parkinsonism-characteristics, pathogenesis and treatment," Nature Reviews Neurology, vol. 11, no. 6, pp. 319-326, 2015.

[164] S. Donnini, R. Solito, E. Cetti et al., “Aß peptides accelerate the senescence of endothelial cellsin vitroandin vivo, impairing angiogenesis," The FASEB Journal, vol. 24, no. 7, pp. 2385-2395, 2010.

[165] R. Solito, F. Corti, C.-H. Chen et al., "Mitochondrial aldehyde dehydrogenase-2 activation prevents -amyloid-induced endothelial cell dysfunction and restores angiogenesis," Journal of Cell Science, vol. 126, no. 9, pp. 1952-1961, 2013.

[166] W. Chen, Y. Chan, W. Wan, Y. Li, and C. Zhang, "A $\beta 1-42$ induces cell damage via RAGE-dependent endoplasmic reticulum stress in bEnd.3 cells," Experimental Cell Research, vol. 362, no. 1, pp. 83-89, 2018.

[167] S. Donnini, S. Cantara, L. Morbidelli, A. Giachetti, and M. Ziche, "FGF-2 overexpression opposes the beta amyloid toxic injuries to the vascular endothelium," Cell Death \& Differentiation, vol. 13, no. 7, pp. 1088-1096, 2006.

[168] R. Solito, F. Corti, S. Fossati et al., "Dutch and arctic mutant peptides of $\beta$ amyloid1-40 differentially affect the FGF-2 pathway in brain endothelium," Experimental Cell Research, vol. 315, no. 3, pp. 385-395, 2009.

[169] S.-J. Cho, M. H. Park, C. Han, K. Yoon, and Y. H. Koh, "VEGFR2 alteration in Alzheimer's disease," Scientific Reports, vol. 7, no. 1, p. 17713, 2017.

[170] N. S. Patel, V. S. Mathura, C. Bachmeier et al., “Alzheimer's $\beta$-amyloid peptide blocks vascular endothelial growth factor mediated signaling via direct interaction with VEGFR-2," Journal of Neurochemistry, vol. 112, no. 1, pp. 66-76, 2010.

[171] S. Hayashi, N. Sato, A. Yamamoto et al., "Alzheimer diseaseassociated peptide, amyloid $\beta 40$, inhibits vascular regeneration with induction of endothelial autophagy," Arteriosclerosis, Thrombosis, and Vascular Biology, vol. 29, no. 11, pp. 1909-1915, 2009.

[172] D. Cifuentes, M. Poittevin, E. Dere et al., "Hypertension accelerates the progression of Alzheimer-like pathology in a mouse model of the disease," Hypertension, vol. 65, no. 1, pp. 218-224, 2015.

[173] L. V. d'Uscio, T. He, and Z. S. Katusic, "Expression and processing of amyloid precursor protein in vascular endothelium," Physiology, vol. 32, no. 1, pp. 20-32, 2017.

[174] S. Cantara, S. Donnini, L. Morbidelli et al., "Physiological levels of amyloid peptides stimulate the angiogenic response through FGF-2," The FASEB Journal, vol. 18, no. 15, pp. 1943-1945, 2004.

[175] D. J. Cameron, C. Galvin, T. Alkam et al., “Alzheimer'srelated peptide amyloid- $\beta$ plays a conserved role in angiogenesis," PLoS One, vol. 7, no. 7, article e39598, 2012.

[176] U. C. Müller, T. Deller, and M. Korte, "Not just amyloid: physiological functions of the amyloid precursor protein family," Nature Reviews Neuroscience, vol. 18, no. 5, pp. 281-298, 2017.

[177] A. H. Bhat, K. B. Dar, S. Anees et al., "Oxidative stress, mitochondrial dysfunction and neurodegenerative diseases; a mechanistic insight," Biomedicine \& Pharmacotherapy, vol. 74, pp. 101-110, 2015.
[178] C.-C. Chiu, T.-H. Yeh, S.-C. Lai et al., "Neuroprotective effects of aldehyde dehydrogenase 2 activation in rotenoneinduced cellular and animal models of parkinsonism," Experimental Neurology, vol. 263, pp. 244-253, 2015.

[179] C.-H. Chen, J. C. B. Ferreira, E. R. Gross, and D. MochlyRosen, "The role of mitochondrial aldehyde dehydrogenase 2 (ALDH2) in neuropathology and neurodegeneration," Acta Neurologica Taiwanica, vol. 25, no. 4, pp. 111-123, 2016.

[180] C.-H. Chen, J. C. B. Ferreira, E. R. Gross, and D. MochlyRosen, "Targeting aldehyde dehydrogenase 2: new therapeutic opportunities," Physiological Reviews, vol. 94, no. 1, pp. 134, 2014

[181] S.-Y. Li, M. Gomelsky, J. Duan et al., "Overexpression of aldehyde dehydrogenase-2 (ALDH2) transgene prevents acetaldehyde-induced cell injury in human umbilical vein endothelial cells," Journal of Biological Chemistry, vol. 279, no. 12, pp. 11244-11252, 2004.

[182] G. Nannelli, E. Terzuoli, V. Giorgio et al., "ALDH2 activity reduces mitochondrial oxygen reserve capacity in endothelial cells and induces senescence properties," Oxidative Medicine and Cellular Longevity, vol. 2018, 13 pages, 2018.

[183] G. Nannelli, M. Ziche, S. Donnini, and L. Morbidelli, "Endothelial aldehyde dehydrogenase 2 as a target to maintain vascular wellness and function in ageing," Biomedicines, vol. 8, no. 1, p. 4, 2020.

[184] Y. D’Souza, A. Elharram, R. Soon-Shiong, R. D. Andrew, and B. M. Bennett, "Characterization of Aldh2-/- mice as an agerelated model of cognitive impairment and Alzheimer's disease," Molecular Brain, vol. 8, no. 1, p. 27, 2015.

[185] C.-H. Chen, G. R. Budas, E. N. Churchill, M.-H. Disatnik, T. D. Hurley, and D. Mochly-Rosen, "Activation of aldehyde dehydrogenase-2 reduces ischemic damage to the heart," Science, vol. 321, no. 5895, pp. 1493-1495, 2008.

[186] H. E. Nursten, The Maillard Reaction, Royal Society of Chemistry, Cambridge, 2007.

[187] M. A. Grillo and S. Colombatto, "Advanced glycation endproducts (AGEs): involvement in aging and in neurodegenerative diseases," Amino Acids, vol. 35, no. 1, pp. 2936, 2008.

[188] S. R. Thorpe and J. W. Baynes, "Maillard reaction products in tissue proteins: new products and new perspectives," Amino Acids, vol. 25, no. 3-4, pp. 275-281, 2003.

[189] E. Diamanti-Kandarakis, S. Palimeri, and E. Palioura, "Current perspectives on the health risks associated with the consumption of advanced glycation end products: recommendations for dietary management," Diabetes, Metabolic Syndrome and Obesity: Targets and Therapy, vol. 8, p. $415,2015$.

[190] M. Takeuchi, S. Kikuchi, N. Sasaki et al., "Involvement of advanced glycation end-products (AGEs) in Alzheimer's disease," Current Alzheimer Research, vol. 1, no. 1, pp. 39-46, 2004.

[191] C. Angeloni, L. Zambonin, and S. Hrelia, "Role of methylglyoxal in Alzheimer's disease," BioMed Research International, vol. 2014, 12 pages, 2014.

[192] P. J. Thornalley, "Pharmacology of methylglyoxal: formation, modification of proteins and nucleic acids, and enzymatic detoxification-a role in pathogenesis and antiproliferative chemotherapy," General Pharmacology: The Vascular System, vol. 27, no. 4, pp. 565-573, 1996. 
[193] P. J. Thornalley, "Dicarbonyl intermediates in the Maillard reaction," Annals of the New York Academy of Sciences, vol. 1043, no. 1, pp. 111-117, 2005.

[194] A.-L. Bulteau, P. Verbeke, I. Petropoulos, A.-F. Chaffotte, and B. Friguet, "Proteasome inhibition in glyoxal-treated fibroblasts and resistance of glycated glucose-6-phosphate dehydrogenase to $20 \mathrm{~S}$ proteasome degradation in vitro," Journal of Biological Chemistry, vol. 276, no. 49, pp. 45662-45668, 2001.

[195] P. S. Sachdev, L. Zhuang, N. Braidy, and W. Wen, "Is Alzheimer's a disease of the white matter?," Current Opinion in Psychiatry, vol. 26, no. 3, pp. 244-251, 2013.

[196] J. F. Honek, “Glyoxalase biochemistry," Biomolecular Concepts, vol. 6, no. 5-6, pp. 401-414, 2015.

[197] G. Delpierre and E. Van Schaftingen, "Fructosamine 3kinase, an enzyme involved in protein deglycation," Biochemical Society transactions, vol. 31, no. 6, pp. 1354-1357, 2003.

[198] H. Sakiyama, M. Takahashi, T. Yamamoto et al., "The internalization and metabolism of 3-deoxyglucosone in human umbilical vein endothelial cells," The Journal of Biochemistry, vol. 139, no. 2, pp. 245-253, 2006.

[199] M. Brownlee, "The Pathobiology of diabetic complications: a unifying mechanism," Diabetes, vol. 54, no. 6, pp. 1615-1625, 2005.

[200] J. Juranek, R. Ray, M. Banach, and V. Rai, "Receptor for advanced glycation end-products in neurodegenerative diseases," Reviews in the Neurosciences, vol. 26, no. 6, pp. 691698, 2015.

[201] S.-Y. Ko, H.-A. Ko, K.-H. Chu et al., "The possible mechanism of advanced glycation end products (AGEs) for Alzheimer's disease," PLoS One, vol. 10, no. 11, article e0143345, 2015.

[202] L. Sessa, E. Gatti, F. Zeni et al., "The receptor for advanced glycation end-products (RAGE) is only present in mammals, and belongs to a family of cell adhesion molecules (CAMs)," PLoS One, vol. 9, no. 1, article e86903, 2014.

[203] G. Sorci, F. Riuzzi, I. Giambanco, and R. Donato, "RAGE in tissue homeostasis, repair and regeneration," Biochimica et Biophysica Acta (BBA) - Molecular Cell Research, vol. 1833, no. 1, pp. 101-109, 2013.

[204] M. Takeuchi and S. Yamagishi, "Involvement of toxic AGEs (TAGE) in the pathogenesis of diabetic vascular complications and Alzheimer's disease," Journal of Alzheimer's Disease, vol. 16, no. 4, pp. 845-858, 2009.

[205] P. Younessi and A. Yoonessi, "Advanced glycation endproducts and their receptor-mediated roles: inflammation and oxidative stress," Iranian Journal of Medical Sciences, vol. 36, no. 3, pp. 154-166, 2011.

[206] C. Logsdon, M. Fuentes, E. Huang, and T. Arumugam, "RAGE and RAGE ligands in cancer," Current Molecular Medicine, vol. 7, no. 8, pp. 777-789, 2007.

[207] A. M. Schmidt, S. Du Yan, S. F. Yan, and D. M. Stern, “The multiligand receptor RAGE as a progression factor amplifying immune and inflammatory responses," Journal of Clinical Investigation, vol. 108, no. 7, pp. 949-955, 2001.

[208] H. Wang, O. Bloom, M. Zhang et al., "HMG-1 as a late mediator of endotoxin lethality in mice," Science, vol. 285, no. 5425, pp. 248-251, 1999.

[209] A. Bierhaus, S. Schiekofer, M. Schwaninger et al., "Diabetesassociated sustained activation of the transcription factor nuclear factor- B," Diabetes, vol. 50, no. 12, pp. 2792-2808, 2001.

[210] A. Bierhaus, P. M. Humpert, M. Morcos et al., "Understanding RAGE, the receptor for advanced glycation end products," Journal of Molecular Medicine, vol. 83, no. 11, pp. 876-886, 2005.

[211] K. Nonaka, Y. Kajiura, M. Bando et al., “Advanced glycation end-products increase IL-6 and ICAM-1 expression via RAGE, MAPK and NF- $\kappa$ B pathways in human gingival fibroblasts," Journal of Periodontal Research, vol. 53, no. 3, pp. 334-344, 2018.

[212] M.-P. Wautier, O. Chappey, S. Corda, D. M. Stern, A. M. Schmidt, and J.-L. Wautier, "Activation of NADPH oxidase by AGE links oxidant stress to altered gene expression via RAGE," American Journal of Physiology-Endocrinology and Metabolism, vol. 280, no. 5, pp. E685-E694, 2001.

[213] Z. Peng, X. Yang, J. Qin et al., “Glyoxalase-1 overexpression reverses defective proangiogenic function of diabetic adipose-derived stem cells in streptozotocin-induced diabetic mice model of critical limb ischemia," Stem Cells Translational Medicine, vol. 6, no. 1, pp. 261-271, 2017.

[214] W. Cai, J. C. He, L. Zhu, X. Chen, G. E. Striker, and H. Vlassara, "AGE-receptor-1 counteracts cellular oxidant stress induced by AGEs via negative regulation of p66shcdependent FKHRL1 phosphorylation," American Journal of Physiology-Cell Physiology, vol. 294, no. 1, pp. C145-C152, 2008.

[215] C. J. He, T. Koschinsky, C. Buenting, and H. Vlassara, "Presence of diabetic complications in type 1 diabetic patients correlates with low expression of mononuclear cell AGEreceptor-1 and elevated serum AGE," Molecular Medicine, vol. 7, no. 3, pp. 159-168, 2001.

[216] J. Li, D. Liu, L. Sun, Y. Lu, and Z. Zhang, “Advanced glycation end products and neurodegenerative diseases: mechanisms and perspective," Journal of the Neurological Sciences, vol. 317 , no. $1-2$, pp. 1-5, 2012.

[217] J. B. Schulz, J. Lindenau, J. Seyfried, and J. Dichgans, "Glutathione, oxidative stress and neurodegeneration," European Journal of Biochemistry, vol. 267, no. 16, pp. 4904-4911, 2000.

[218] H. V. Miranda and T. F. Outeiro, "The sour side of neurodegenerative disorders: the effects of protein glycation," The Journal of Pathology, vol. 221, no. 1, pp. 13-25, 2010.

[219] P. Salahuddin, G. Rabbani, and R. Khan, "The role of advanced glycation end products in various types of neurodegenerative disease: a therapeutic approach," Cellular and Molecular Biology Letters, vol. 19, no. 3, pp. 407-437, 2014.

[220] G. Münch, S. Mayer, J. Michaelis et al., "Influence of advanced glycation end-products and AGE-inhibitors on nucleation- dependent polymerization of $\beta$-amyloid peptide," Biochimica et Biophysica Acta (BBA)-Molecular Basis of Disease, vol. 1360, no. 1, pp. 17-29, 1997.

[221] M. D. Ledesma, P. Bonay, and J. Avila, "Tau protein from Alzheimer's disease patients is glycated at its tubulinbinding domain," Journal of Neurochemistry, vol. 65, no. 4, pp. 1658-1664, 1995.

[222] S.-Y. Ko, Y.-P. Lin, Y.-S. Lin, and S.-S. Chang, "Advanced glycation end products enhance amyloid precursor protein expression by inducing reactive oxygen species," Free Radical Biology and Medicine, vol. 49, no. 3, pp. 474-480, 2010.

[223] R. Deane, I. Singh, A. P. Sagare et al., "A multimodal RAGEspecific inhibitor reduces amyloid $\beta$-mediated brain disorder 
in a mouse model of Alzheimer disease," Journal of Clinical Investigation, vol. 122, no. 4, pp. 1377-1392, 2012.

[224] A. König, H. Vicente Miranda, and T. F. Outeiro, “Alphasynuclein glycation and the action of anti-diabetic agents in Parkinson's disease," Journal of Parkinson's Disease, vol. 8, no. 1, pp. 33-43, 2018.

[225] V. Padmaraju, J. J. Bhaskar, U. J. S. Prasada Rao, P. V. Salimath, and K. S. Rao, "Role of advanced glycation on aggregation and DNA binding properties of $\alpha$-synuclein," Journal of Alzheimer's Disease, vol. 24, no. s2, pp. 211-221, 2011.

[226] Y. T. Han, G.-I. Choi, D. Son et al., "Ligand-based design, synthesis, and biological evaluation of 2-aminopyrimidines, a novel series of receptor for advanced glycation end products (RAGE) inhibitors," Journal of Medicinal Chemistry, vol. 55, no. 21, pp. 9120-9135, 2012.

[227] N. Shangari, W. R. Bruce, R. Poon, and P. J. O'Brien, “Toxicity of glyoxals - role of oxidative stress, metabolic detoxification and thiamine deficiency," Biochemical Society Transactions, vol. 31, no. 6, pp. 1390-1393, 2003.

[228] D. Chandler, A. Woldu, A. Rahmadi et al., "Effects of plantderived polyphenols on TNF- $\alpha$ and nitric oxide production induced by advanced glycation endproducts," Molecular Nutrition \& Food Research, vol. 54, no. S2, pp. S141-S150, 2010.

[229] P. G. Dorsey and P. Greenspan, "Inhibition of nonenzymatic protein glycation by pomegranate and other fruit juices," Journal of Medicinal Food, vol. 17, no. 4, pp. 447-454, 2014.

[230] L. Lv, X. Shao, H. Chen, C.-T. Ho, and S. Sang, "Genistein inhibits advanced glycation end product formation by trapping methylglyoxal," Chemical Research in Toxicology, vol. 24, no. 4, pp. 579-586, 2011.

[231] S. Lee and K.-W. Lee, "Protective effect of (-)-epigallocatechin gallate against advanced glycation endproductsinduced injury in neuronal cells," Biological \& Pharmaceutical Bulletin, vol. 30, no. 8, pp. 1369-1373, 2007.

[232] H. F. Zhao, N. Li, Q. Wang, X. J. Cheng, X. M. Li, and T. T. Liu, "Resveratrol decreases the insoluble $A \beta 1-42$ level in hippocampus and protects the integrity of the blood-brain barrier in AD rats," Neuroscience, vol. 310, pp. 641-649, 2015.

[233] K. A. Jhang, J.-S. Park, H.-S. Kim, and Y. H. Chong, "Resveratrol ameliorates Tau hyperphosphorylation at ser396 site and oxidative damage in rat hippocampal slices exposed to vanadate: implication of ERK1/2 and GSK- $3 \beta$ signaling cascades," Journal of Agricultural and Food Chemistry, vol. 65, no. 44, pp. 9626-9634, 2017.

[234] R. Wang, Y. Zhang, J. Li, and C. Zhang, "Resveratrol ameliorates spatial learning memory impairment induced by $\mathrm{A} \beta 1-$ 42 in rats," Neuroscience, vol. 344, pp. 39-47, 2017.

[235] S. Yang, G. Wang, Z. F. Ma et al., "DietaryAdvancedGlycationEnd Products-InducedCognitive impairment in aged ICR mice: protective role of quercetin," Molecular Nutrition \& Food Research, vol. 64, no. 3, article e1901019, 2020.

[236] C. Angeloni, M. Malaguti, B. Rizzo, M. C. Barbalace, D. Fabbri, and S. Hrelia, "Neuroprotective effect of sulforaphane against methylglyoxal cytotoxicity," Chemical Research in Toxicology, vol. 28, no. 6, pp. 1234-1245, 2015.

[237] C. Angeloni, M. Malaguti, and S. Hrelia, "Antiglycative activity of sulforaphane: a new avenue to counteract neurodegeneration?," Neural Regeneration Research, vol. 10, no. 11, pp. 1750-1751, 2015.
[238] C. Angeloni, M. Malaguti, M. Barbalace, and S. Hrelia, "Bioactivity of olive oil phenols in neuroprotection," International Journal of Molecular Sciences, vol. 18, no. 11, p. 2230, 2017.

[239] M. Navarro, F. J. Morales, and S. Ramos, "Olive leaf extract concentrated in hydroxytyrosol attenuates protein carbonylation and the formation of advanced glycation end products in a hepatic cell line (HepG2)," Food Function, vol. 8, no. 3, pp. 944-953, 2017.

[240] L. Giusti, C. Angeloni, M. Barbalace et al., "A proteomic approach to uncover neuroprotective mechanisms of oleocanthal against oxidative stress," International Journal of Molecular Sciences, vol. 19, no. 8, p. 2329, 2018.

[241] C. Angeloni, L. Giusti, and S. Hrelia, "New neuroprotective perspectives in fighting oxidative stress and improving cellular energy metabolism by oleocanthal," Neural Regeneration Research, vol. 14, no. 7, pp. 1217-1218, 2019.

[242] S. Nishimoto, S. Koike, N. Inoue, T. Suzuki, and Y. Ogasawara, "Activation of Nrf2 attenuates carbonyl stress induced by methylglyoxal in human neuroblastoma cells: increase in GSH levels is a critical event for the detoxification mechanism," Biochemical and Biophysical Research Communications, vol. 483, no. 2, pp. 874-879, 2017.

[243] M. J. Goodfellow, A. Borcar, J. L. Proctor, T. Greco, R. E. Rosenthal, and G. Fiskum, "Transcriptional activation of antioxidant gene expression by Nrf2 protects against mitochondrial dysfunction and neuronal death associated with acute and chronic neurodegeneration," Experimental Neurology, vol. 328, p. 113247, 2020. 